\title{
Key Common Genes in Obstructive Sleep Apnea and Lung Cancer are Associated with Prognosis of Lung Cancer Patients
}

\section{Wenjun Wang (D) \\ Lirong $\mathrm{He}$ \\ Chao Ouyang \\ Chong Chen \\ Xiaofeng Xu \\ Xiaoqun Ye}

Department of Respiratory Diseases, The Second Affiliated Hospital of Nanchang University, Nanchang, 330006, Jiangxi, People's Republic of China
Correspondence: Xiaoqun Ye Department of Respiratory Diseases, The Second Affiliated Hospital of Nanchang University, I Minde Road, Nanchang, 330006, Jiangxi, People's Republic of China

Tel +86-13870807068

Fax +86-7916300507

Email5II201663@qq.com
Background: Obstructive sleep apnea (OSA) is associated with an increased risk of lung cancer. This study aimed to identify key common genes in OSA and lung cancer and explore their prognostic value in lung cancer.

Materials and Methods: Transcriptome data of OSA and lung cancer were obtained from the Gene Expression Omnibus (GEO) and The Cancer Genome Atlas (TCGA) database, respectively. Genes associated with OSA and lung cancer were screened by weighted gene co-expression network analysis (WGCNA). Univariate and multivariate Cox regression algorithms were applied to identify key genes and construct the risk score model. Receiver operating characteristic (ROC) curves and a nomogram were performed to evaluate the prognostic value of the risk score. The screened key genes and their roles in prognosis were validated by GEO (GSE30219) analysis.

Results: A total of 104 common genes were screened in OSA and lung cancer by WGCNA. Modulator of apoptosis 1 (MOAP1), chromobox 7 (CBX7), platelet-derived growth factor subunit B (PDGFB), and mitogen-activated protein kinase 3 (MAP2K3) were identified as key genes by univariate and then multivariate Cox regression analyses. The risk score model was constructed on the basis of four gene signatures. ROC curves and the nomogram showed that the risk score had a high accuracy in predicting the survival of patients with lung cancer. In addition, the result of multivariate Cox regression analysis indicated that the risk score was an independent prognostic factor in lung cancer.

Conclusion: This study constructed a unique model for predicting the prognosis of lung cancer patients on the basis of four genes common to OSA and lung cancer. These genes may also serve as candidate genes to improve our knowledge about the underlying mechanism of OSA that leads to an increased risk of lung cancer at the genetic level.

Keywords: lung cancer, obstructive sleep apnea, OSA, weighted gene co-expression network analysis, WGCNA, lung cancer prognosis

\section{Introduction}

Lung cancer ranks first among the common cancer types of the world in men and second in women. ${ }^{1}$ According to statistical data from the American Cancer Society, the numbers of new lung cancer cases and lung cancer deaths have been decreasing, but deaths caused by lung cancer remain more common than deaths caused by breast, prostate, colorectal, and brain cancers combined. ${ }^{1}$ Lung cancer is a heterogeneous disease influenced by constitutional genetic or epigenetic susceptibilities and affected by various environmental factors. ${ }^{2}$ Despite advances in knowledge made about lung cancer-associated risk factors, tumorigenesis, immune 
evasion, development, angiogenesis, metastasis, chemoresistance, and treatment strategies, the disease still brings a huge economic and medical care burden to the world. ${ }^{3}$ In recent years, obstructive sleep apnea (OSA), as a result of rapid economic development and changes in lifestyle, has become more prevalent in numerous countries. ${ }^{4}$ OSA is a complex, multifactorial disease affecting millions of people worldwide, and it may complicate cerebrovascular, cardiovascular, and metabolic diseases. ${ }^{5}$ The key clinical characteristic of OSA is repeated collapse of the upper airway during sleep accompanied with sleep fragments (SFs) and daytime sleepiness, leading to chronic intermittent hypoxia (IH). ${ }^{6}$ The symptoms of and treatments for OSA vary according to severity. Therefore, early diagnosis and management of OSA are critical for promoting treatments and preventing complications.

Epidemiological investigations have indicated that $\mathrm{IH}$ caused by OSA is involved in activating a variety of carcinogenic pathways and contributes to tumorigenesis and the development of cancer. ${ }^{7}$ According to numerous studies, OSA is associated with increased morbidity and mortality in lung cancer and accelerates the progression of lung cancer. ${ }^{8,9}$ Torres et $\mathrm{al}^{10}$ reported that, in female mice, OSA as an independent contributor promoted the aggressiveness of lung cancer through alterations of the host immune response. As a result, the relationship between lung cancer and OSA is increasingly attracting the attention of scholars. Although lung cancer and OSA belong to two different systems, studies have suggested that these two diseases interact with each other and share some identical pathological mechanisms.

However, few studies are focused on the shared genes and common pathogeneses of lung cancer and OSA. It is necessary to screen for genes shared by these two diseases using bioinformatics methods at genetic and molecular levels. In this study, we aimed to identify shared genes between OSA and lung cancer by using weighted gene co-expression network analysis (WGCNA). WGCNA is an advanced method that describes the molecular mechanism and reconstructing co-expression networks of genes using an integrative method. ${ }^{11,12}$ We also explored the prognostic value of these screened genes for lung cancer to potentially identify new diagnostic biomarkers or therapeutic targets of lung cancer.

\section{Materials and Methods}

\section{Data Source}

RNA sequencing (RNA-seq) data of 34 OSA and eight control samples were downloaded from the GSE135917 dataset.
Gene expression profile and clinical data of 1006 lung cancer samples and 107 normal samples were downloaded from The Cancer Genome Atlas (TCGA) (https://www.cancer.gov/ about-nci/organization/ccg/research/structural-genomics /tcga) database and used as training set. GSE30219, including RNA-seq data and clinical information of 293 lung cancer samples and 14 normal samples, was downloaded from the Gene Expression Omnibus (GEO) (https://www.ncbi.nlm. nih.gov/geo) database and used as validation set.

\section{WGCNA Analysis}

Sample clustering tree maps were constructed to detect and eliminate outliers in the GSE135917 and TCGA lung cancer datasets, respectively. Then, the pick soft threshold function of WGCNA was used to calculate $\beta$ from 1 to 30 to select the best soft threshold. According to the selected soft threshold, the adjacency matrix was converted to a topological overlap matrix for constructing the network, and the gene dendrogram and module color were established by using the degree of dissimilarity. We divided the initial module again through dynamic tree cutting and merged similar modules. The Pearson correlation coefficient between the module eigengenes and sample traits was calculated to identify the significantly relevant modules associated with OSA and lung cancer. In addition, module preservation analysis was performed to calculate the $\mathrm{Z}$ summary score. A $\mathrm{Z}$ summary score $>10$ indicates strong evidence of module preservation, whereas a $Z$ summary score $<2$ or a score between 2 and $<10$ indicates no evidence or weak evidence, respectively, of module preservation.

\section{Biological Function Analysis}

Gene Ontology (GO) and Kyoto Encyclopedia of Genes and Genomes (KEGG) pathway enrichment of common genes in OSA and lung cancer was analyzed by Cluster Profiler R package. ${ }^{13}$ Additionally, Gene Set Enrichment Analysis (GSEA) was performed to investigate the molecular mechanisms of prognostic gene signatures. GO and KEGG gene sets were downloaded from the MSigDB database (http://software.broadinstitute.org/gsea/msigdb/ index.jsp).

\section{Construction and Validation of the Risk Score Model}

Univariate Cox regression analysis was conducted to screen genes significantly related to the survival ( $\mathrm{P}$ value $<0.05)$. Furthermore, multivariate Cox regression analysis 
was conducted and identified four signature genes. Then, the risk score was calculated using the following formula:

$$
\begin{aligned}
& (\text { ExpGene } 1 \times \text { Coef } 1)+(\text { ExpGene } 2 \times \text { Coef } 2)+(\text { ExpGene } 3 \\
& \times \text { Coef } 3)+(\text { ExpGene } 4 \times \text { Coef } 4)
\end{aligned}
$$

in which Coef represents the regression coefficients of genes and Exp is the normalized expression values of each signature gene. According to the median value of the risk score, patients with lung cancer were divided into high-risk and low-risk groups. The overall survival of high-risk and low-risk groups was analyzed by Kaplan-Meier analysis. To evaluate the accuracy of the risk score model, the receiver operating characteristics (ROC) curve was plotted using "survival ROC" in R package. Univariate and multivariate analyses were then performed to determine whether the risk score was an independent prognostic factor. A nomogram was constructed for clinical use. The performance of the nomogram was assessed by calibration curves.

\section{Statistical Analysis}

All data were analyzed by R (version 4.0.0, https://www. r-project.org/). The Wilcoxon test was used to compare the expressions of four prognostic gene signatures between lung cancer and normal samples. A P value less than 0.05 was considered statistically significant.

\section{Results}

\section{Identification of Common Genes in OSA and Lung Cancer by WGCNA}

According to the sample clustering results, one outlier sample in GSE135917 in TCGA were detected and eliminated (Figure 1A), and then the sample dendrogram and trait heatmaps were built (Figure 1B). 16 outlier samples in TCGA were detected and eliminated (Figure 2A), and then the sample dendrogram and trait heatmaps were built (Figure 2B). Using the pick soft threshold function of WGCNA, we found that the optimal soft threshold power was 18 for GSE135917 samples (Figure 1C) and 5 for TCGA samples (Figure 2C); in both sample sets, the $\mathrm{R}^{2}$ was approximately 0.9 . Sixteen modules were finally identified in GSE135917 (Figure 1D), and 35 modules were identified in TCGA (Figure 2D) from the coexpression network after merging of similar modules. After calculating the correlations between modules and OSA or lung cancer, we plotted the corresponding heatmaps of module-trait relationships (Figures 1E and 2E). Furthermore, we performed the module preservation to calculate the $\mathrm{Z}$ summary scores of each module in Figures $1 \mathrm{E}$ and $2 \mathrm{E}$ (Figures $1 \mathrm{~F}$ and $2 \mathrm{~F}$ ).
Then, key modules were screened with the following criteria: $\mid$ cor $\mid>0.5, \mathrm{P}<0.05$, and $\mathrm{Z}$ summary score $>10$. Dark gray and ivory modules, associated with OSA (Figure 3A), and blue and yellow modules, associated with lung cancer (Figure 3B), were identified as key modules. To obtain common genes in OSA and lung cancer, we overlapped the genes in key modules of OSA and lung cancer and obtained 104 genes common to OSA and lung cancer (Figure 3C).

\section{Biological Function Analysis of Common Genes in OSA and Lung Cancer}

We also conducted GO and KEGG pathway enrichment analyses to investigate the biological functions of the 104 common genes. No KEGG pathway was significantly enriched. A total of $10 \mathrm{GO}$ terms were significantly enriched: hemoglobin metabolic process, positive regulation of blood vessel endothelial cell migration, epithelial cell migration, endothelial cell migration, epithelium migration, tissue migration, regulation of epithelial cell migration, regulation of endothelial cell migration, positive regulation of glycolytic process, and positive regulation of epithelial cell migration (Table 1 and Figure 3D).

\section{Identification of Key Genes Associated with Prognosis of Lung Cancer}

We also investigated the prognostic value of 104 common genes in lung cancer by univariate Cox regression algorithm analysis. A total of 14 genes were significantly associated with prognosis $(\mathrm{P}<0.05)$, among which nuclear factor kappa B inhibitor interacting Ras like 1 (NKIRAS1), $M O A P 1, C B X 7$, transformer 2 alpha homolog (TRA2A), and acetyl-CoA acetyltransferase 1 (ACAT1) played a protective role (hazard ratio $[\mathrm{HR}]<1$ ), and the remaining nine genes were risk factors (HR $>1$, Figure 4A). To obtain more robust signature genes, these 14 genes were then selected for multivariate Cox regression algorithm analysis. MOAP1, CBX7, PDGFB, and MAP2K3 were identified as key prognostic genes (Figure 4B). The expressions of $M O A P 1, C B X 7, P D G F B$, and $M A P 2 K 3$ were significantly higher in normal samples compared with lung cancer samples in TCGA (Figure 4C). Their expressions were also validated in GSE30219. Consistent with the results in TCGA, the expressions of MOAP1, $C B X 7, P D G F B$, and $M A P 2 K 3$ were downregulated in GSE30219 lung cancer samples (Figure 4D). 
A

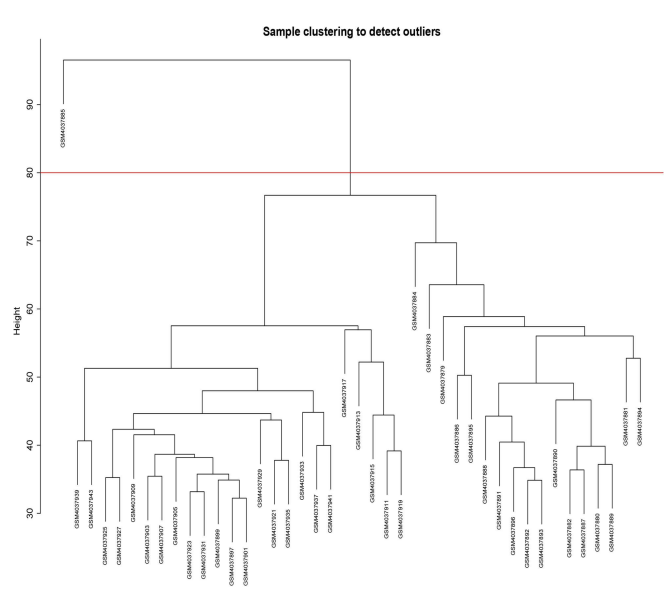

C

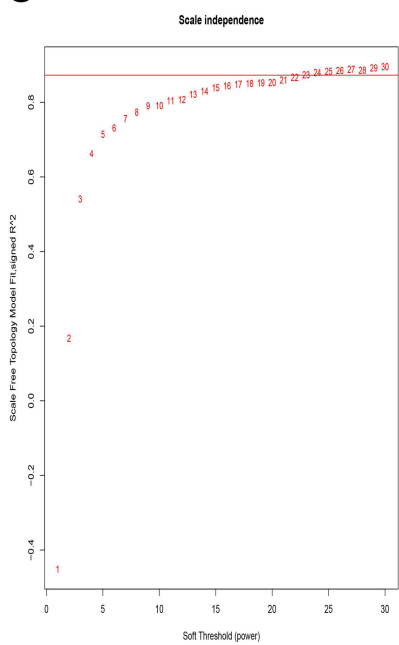

$\mathbf{E}$

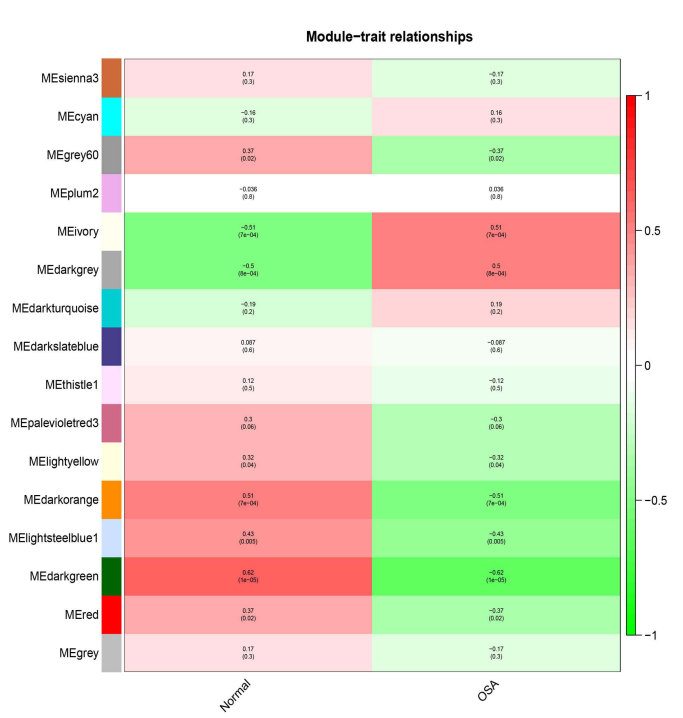

B
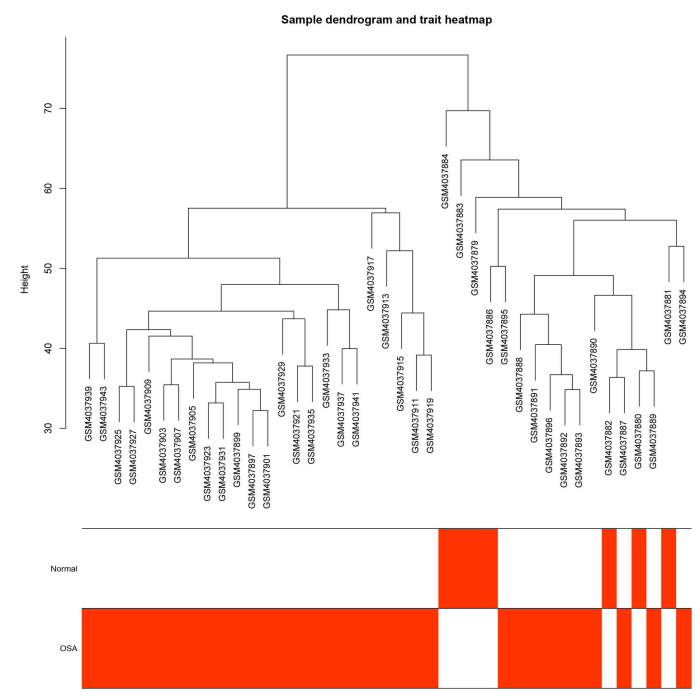

D
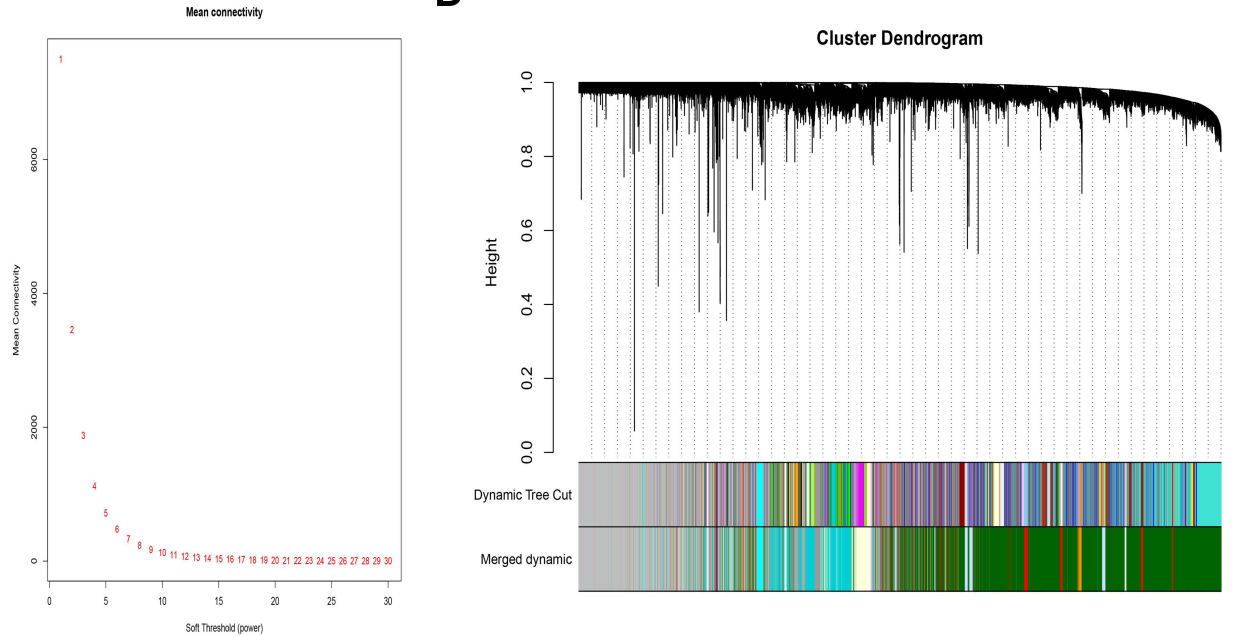

$\mathbf{F}$

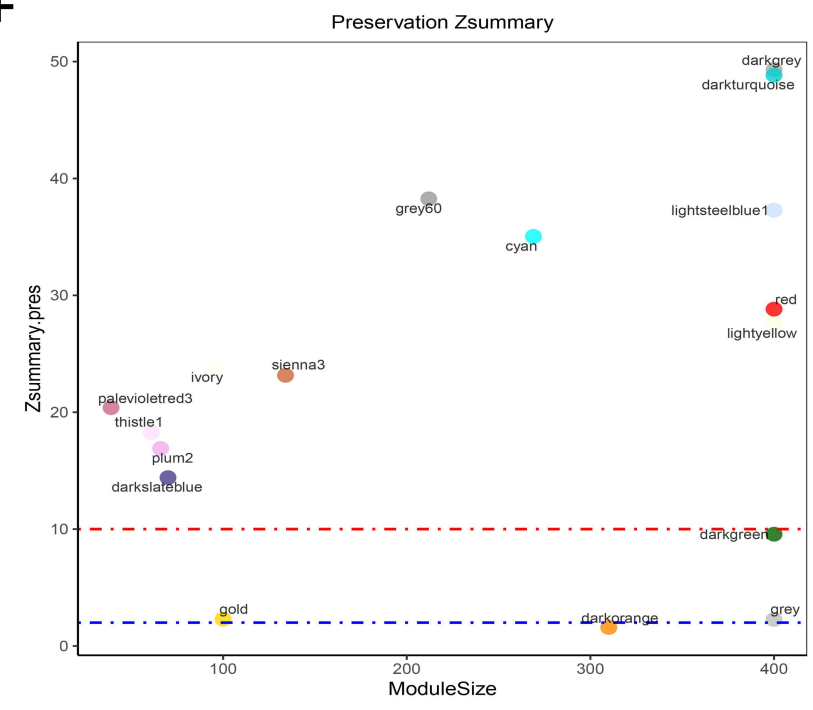

Figure I WGCNA of the OSA dataset (GSEI359I7). (A) The sample clustering results. (B) The sample dendrogram and trait heatmaps. (C) A soft threshold of I8 was the most suitable value to OSA. (D) Sixteen modules were related to OSA. (E) The corresponding heatmaps of module-trait relationships. (F) The Zsummary scores of I6 modules calculated by module preservation.

Abbreviations: OSA, Obstructive sleep apnea; WGCNA, weighted gene co-expression network analysis. 
A

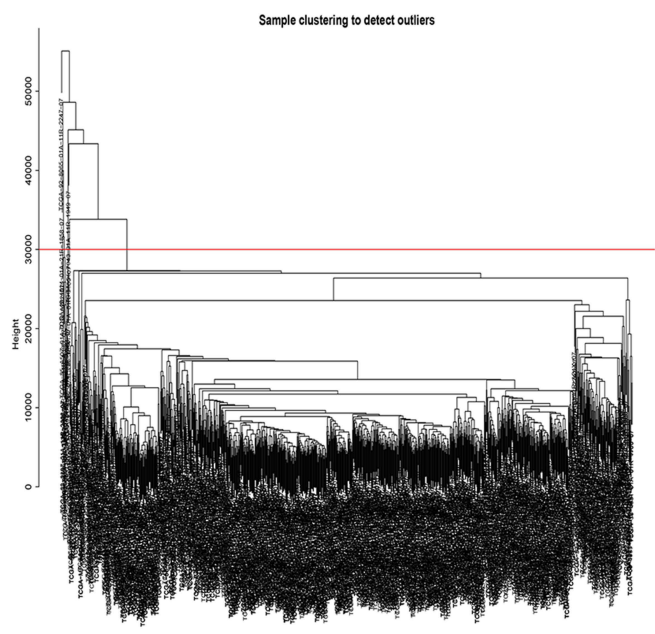

C
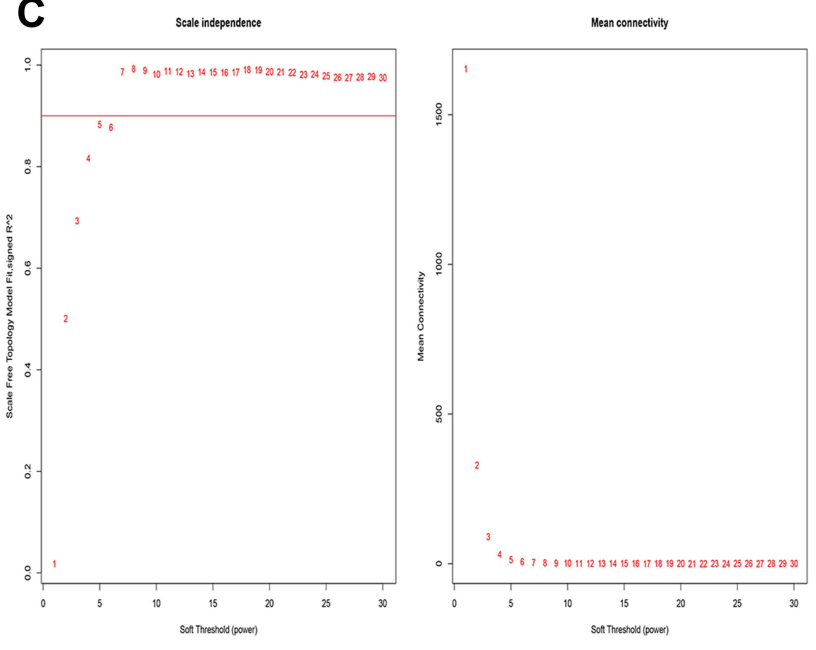

$\mathbf{E}$

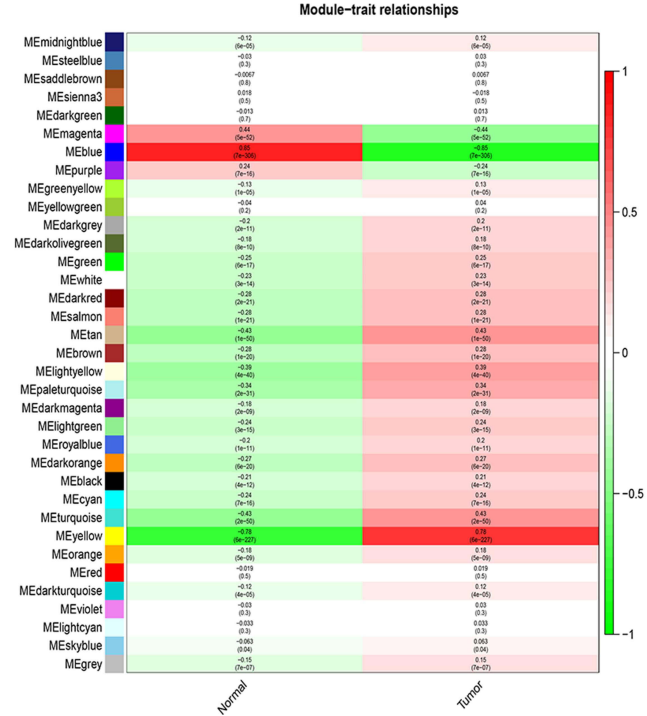

B
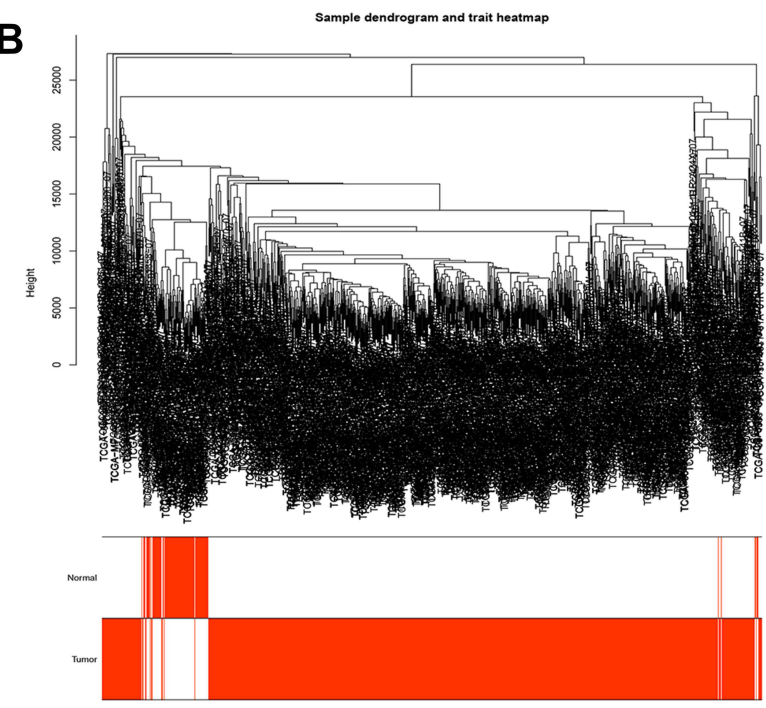

D

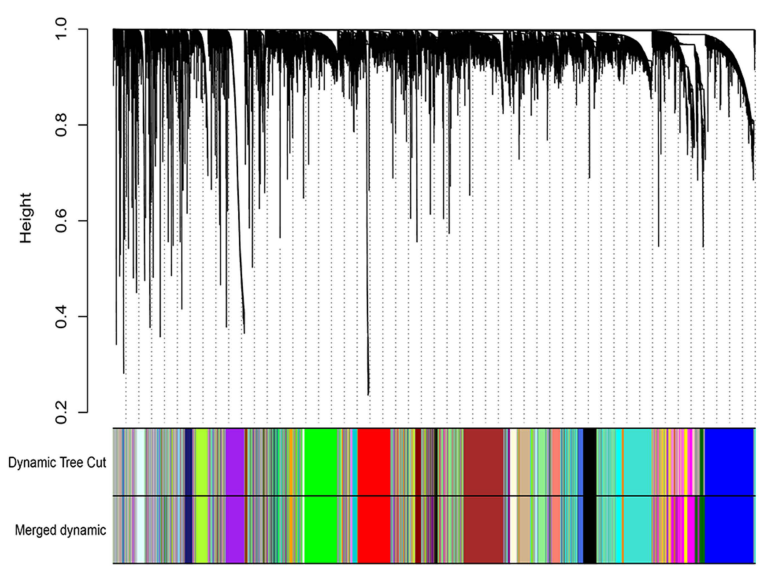

$\mathbf{F}$

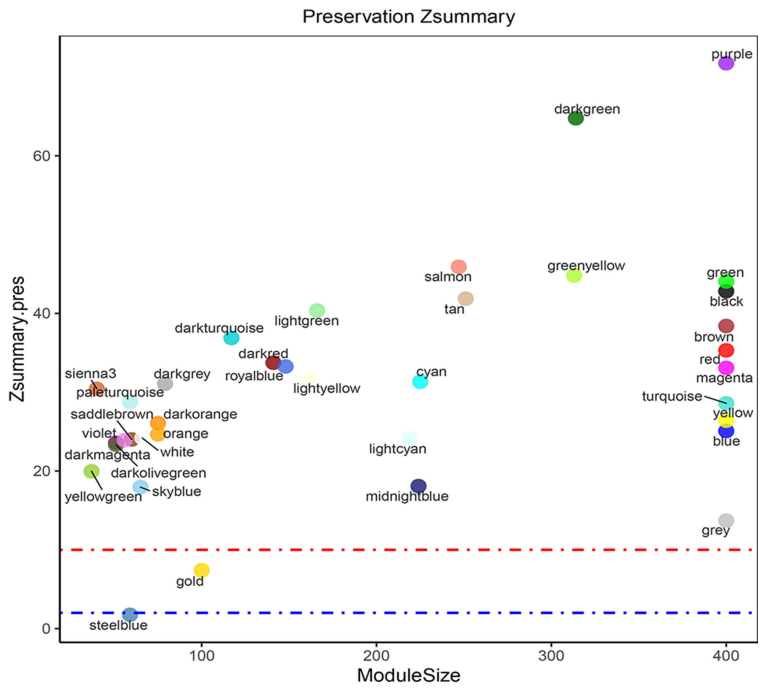

Figure 2 WGCNA of lung cancer dataset in The Cancer Genome Atlas (TCGA). (A) The sample clustering results. (B) The sample dendrogram and trait heatmaps. (C) A soft threshold of five was the most suitable value to lung cancer. (D) Thirty-five modules were related to lung cancer. (E) The corresponding heatmaps of module-trait relationships. (F) The Zsummary scores of 35 modules calculated by module preservation. Abbreviation: WGCNA, weighted gene co-expression network analysis. 


\section{A}

\begin{tabular}{cccc}
\hline moduleColor & cor & pvalue & $Z$ \\
\hline darkgrey & -0.62 & $1.00 \mathrm{E}-05$ & 49.319321 \\
\hline ivory & 0.51 & $7.00 \mathrm{E}-04$ & 23.848466 \\
\hline
\end{tabular}

B

\begin{tabular}{cccc}
\hline moduleColor & cor & pvalue & $Z$ \\
\hline blue & -0.85 & $7.00 \mathrm{E}-306$ & 25.074106 \\
\hline yellow & 0.78 & $6.00 \mathrm{E}-227$ & 26.372551 \\
\hline
\end{tabular}

C

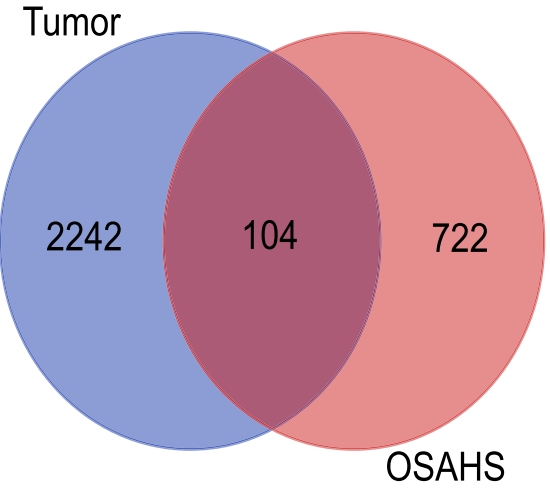

D

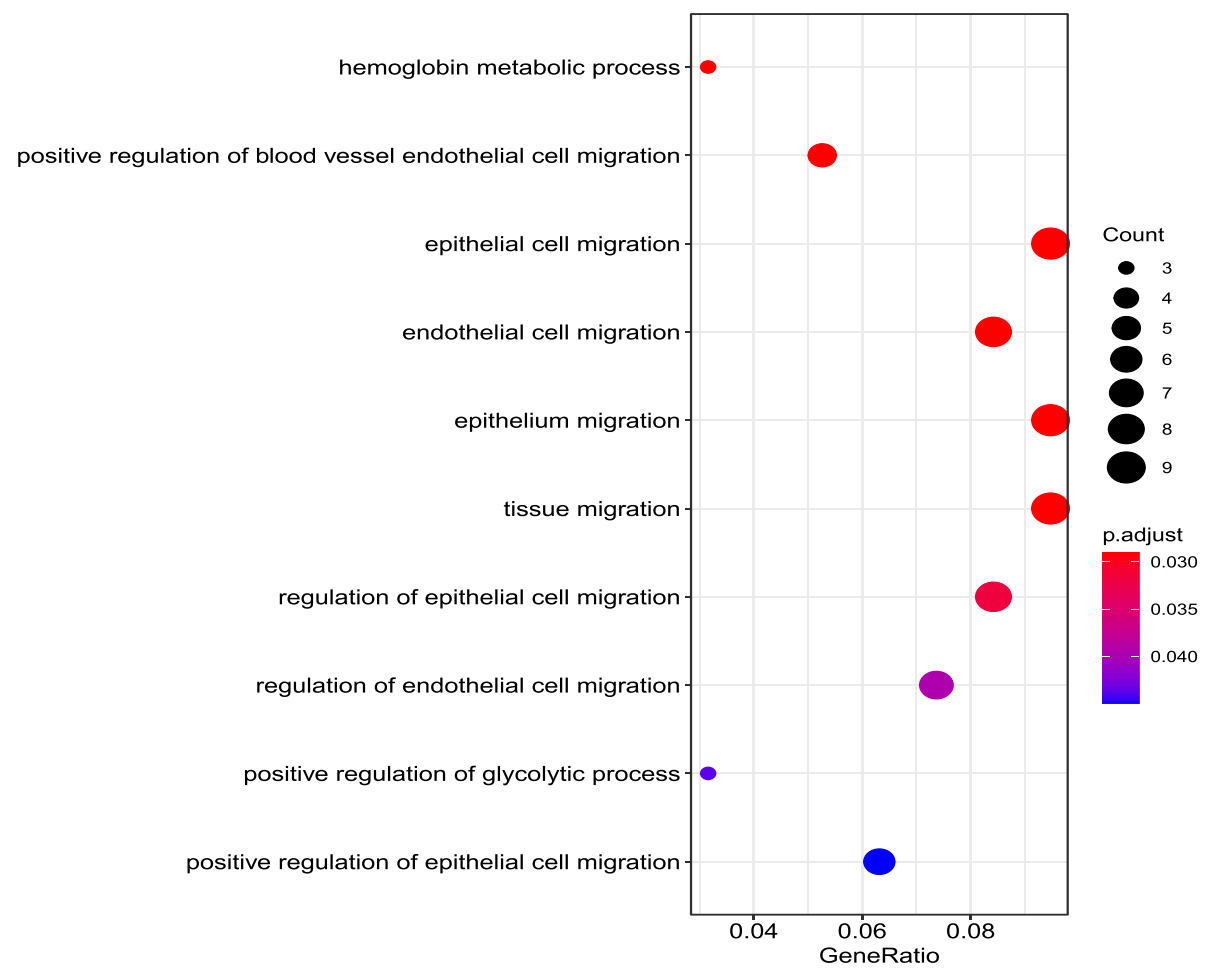

Figure 3 Screening for key modules and common genes. (A) Dark gray and ivory modules were screened in OSA and (B) blue and yellow modules were screened in lung cancer. (C) A total of 104 overlapped common genes in key modules of OSA and lung cancer were screened. (D) Gene Ontology analysis of 104 common genes in OSA and lung cancer.

Abbreviation: OSA, obstructive sleep apnea. 
Table I Functional Enrichment Analysis and the Identified 10 Enriched Pathways

\begin{tabular}{|c|c|c|c|c|c|c|c|c|}
\hline ID & Description & $\begin{array}{l}\text { Gene } \\
\text { Ratio }\end{array}$ & $\begin{array}{l}\text { Bg } \\
\text { Ratio }\end{array}$ & p value & p.Adjust & q value & Gene ID & Count \\
\hline GO:0020027 & $\begin{array}{l}\text { Hemoglobin metabolic } \\
\text { process }\end{array}$ & $3 / 95$ & $\begin{array}{l}14 \mid \\
18,670\end{array}$ & $4.46 \mathrm{E}-05$ & 0.029085 & 0.027236 & ADDI/EIF2AKI/HIFIA & 3 \\
\hline GO:0043536 & $\begin{array}{l}\text { Positive regulation of } \\
\text { blood vessel endothelial } \\
\text { cell migration }\end{array}$ & $5 / 95$ & $\begin{array}{l}79 / \\
18,670\end{array}$ & $5.13 \mathrm{E}-05$ & 0.029085 & 0.027236 & $\begin{array}{l}\text { ETSI/PDGFB/SRPX2/HIFIA/ } \\
\text { MAP2K } 3\end{array}$ & 5 \\
\hline GO:001063I & Epithelial cell migration & $9 / 95$ & $\begin{array}{l}352 / \\
18,670\end{array}$ & $7.68 \mathrm{E}-05$ & 0.029085 & 0.027236 & $\begin{array}{l}\text { ETSI/MAPRE2/PDGFB/ } \\
\text { PECAMI/PTPRM/SRPX2/ } \\
\text { SYNJ2BP/HIFI A/MAP2K3 }\end{array}$ & 9 \\
\hline GO:0043542 & Endothelial cell migration & $8 / 95$ & $\begin{array}{l}274 / \\
18,670\end{array}$ & $7.84 \mathrm{E}-05$ & 0.029085 & 0.027236 & $\begin{array}{l}\text { ETSI/PDGFB/PECAMI/PTPRM/ } \\
\text { SRPX2/SYNJ2BP/HIFIA/MAP2K3 }\end{array}$ & 8 \\
\hline GO:0090132 & Epithelium migration & $9 / 95$ & $\begin{array}{l}355 / \\
18,670\end{array}$ & $8.19 \mathrm{E}-05$ & 0.029085 & 0.027236 & $\begin{array}{l}\text { ETSI/MAPRE2/PDGFB/ } \\
\text { PECAMI/PTPRM/SRPX2/ } \\
\text { SYNJ2BP/HIFIA/MAP2K3 }\end{array}$ & 9 \\
\hline GO:0090130 & Tissue migration & $9 / 95$ & $\begin{array}{l}36 \mid / \\
18,670\end{array}$ & $9.3 \mathrm{IE}-05$ & 0.029085 & 0.027236 & $\begin{array}{l}\text { ETSI/MAPRE2/PDGFB/ } \\
\text { PECAMI/PTPRM/SRPX2/ } \\
\text { SYNJ2BP/HIFIA/MAP2K3 }\end{array}$ & 9 \\
\hline GO:00I0632 & $\begin{array}{l}\text { Regulation of epithelial } \\
\text { cell migration }\end{array}$ & $8 / 95$ & $\begin{array}{l}291 / \\
18,670\end{array}$ & 0.000118 & 0.031869 & 0.029843 & $\begin{array}{l}\text { ETSI/MAPRE2/PDGFB/PTPRM/ } \\
\text { SRPX2/SYNJ2BP/HIFIA/MAP2K3 }\end{array}$ & 8 \\
\hline GO:0010594 & $\begin{array}{l}\text { Regulation of endothelial } \\
\text { cell migration }\end{array}$ & $7 / 95$ & $\begin{array}{l}229 / \\
18,670\end{array}$ & 0.000168 & 0.039517 & 0.037005 & $\begin{array}{l}\text { ETSI/PDGFB/PTPRM/SRPX2/ } \\
\text { SYNJ2BP/HIFIA/MAP2K3 }\end{array}$ & 7 \\
\hline GO:004582I & $\begin{array}{l}\text { Positive regulation of } \\
\text { glycolytic process }\end{array}$ & $3 / 95$ & $\begin{array}{l}23 / \\
18,670\end{array}$ & 0.000209 & 0.043736 & 0.040955 & ENTPD5/HIFIA/PRKAA2 & 3 \\
\hline GO:0010634 & $\begin{array}{l}\text { Positive regulation of } \\
\text { epithelial cell migration }\end{array}$ & $6 / 95$ & $\begin{array}{l}171 / \\
18,670\end{array}$ & 0.000239 & 0.044934 & 0.042077 & $\begin{array}{l}\text { ETSI/MAPRE2/PDGFB/SRPX2/ } \\
\text { HIFIA/MAP2K3 }\end{array}$ & 6 \\
\hline
\end{tabular}

Abbreviation: GO, Gene Ontology.

\section{Construction and Validation of the Risk Score Model by Prognostic Gene Signatures}

According to the coefficients of MOAP1, CBX7, PDGFB, and MAP2K3 in Table 2, we calculated the risk scores of each patient. On the basis of the median of the risk scores, the patients in TCGA training set were divided into highand low-risk groups (Figure 5A). The expressions of $M O A P 1, C B X 7, P D G F B$, and $M A P 2 K 3$ in high- and lowrisk groups were displayed in a heatmap (Figure 5B). A significant survival difference $(\mathrm{P}<0.0001)$ was found between high- and low-risk groups (Figure $5 \mathrm{C}$ ). Moreover, we plotted ROC curves to study the predictive efficiency of the risk score model. The results showed that the risk score model had high accuracy in predicting the survival of patients with lung cancer when areas under the curves
(AUC) equaled 0.707 for 1-, 3-, 5-, 7-, and 10-year timepoints (Figure 5D). The same results were obtained in the GSE30219 validation set (Figure 6A-D).

Next, we performed univariate and multivariate analyses in TCGA training set to determine whether the risk score was an independent prognostic factor. Univariate analysis showed that $\mathrm{M}$ stage, $\mathrm{N}$ stage, $\mathrm{T}$ stage, pathologic stage, and risk score were significantly correlated with prognosis (Figure 7A). Multivariate analysis using these correlated factors indicated that risk score remained remarkably associated with prognosis (Figure 7B). Similar results were obtained in the GSE30219 validation set (Figure 7C and D).

\section{Construction and Analysis of the}

\section{Nomogram}

We used the factors significantly associated with prognosis in multivariate analysis ( $\mathrm{M}$ stage, $\mathrm{N}$ stage, $\mathrm{T}$ stage, and 
A

\begin{tabular}{|c|c|c|}
\hline & pvalue & Hazard ratio \\
\hline NKIRAS1 & 0.0048 & $0.65(0.49-0.88)$ \\
\hline MOAP1 & $4 e-04$ & $0.72(0.6-0.86)$ \\
\hline CBX7 & 0.0077 & $0.8(0.68-0.94)$ \\
\hline TRA2A & 0.038 & $0.8(0.65-0.99)$ \\
\hline ACAT1 & 0.04 & $0.85(0.73-0.99)$ \\
\hline BASP1 & 0.03 & $1.1(1-1.2)$ \\
\hline PLOD2 & 0.023 & $1.1(1-1.2)$ \\
\hline HES4 & 0.038 & $1.1(1-1.3)$ \\
\hline PPP1R14B & 0.041 & $1.2(1-1.4)$ \\
\hline INTS1 & 0.015 & $1.2(1-1.4)$ \\
\hline RAB10 & 0.045 & $1.2(1-1.4)$ \\
\hline PDGFB & 0.002 & $1.2(1.1-1.4)$ \\
\hline МАР2К3 & 0.015 & $1.2(1-1.5)$ \\
\hline BZW1 & 0.011 & $1.3(1.1-1.5)$ \\
\hline
\end{tabular}

c

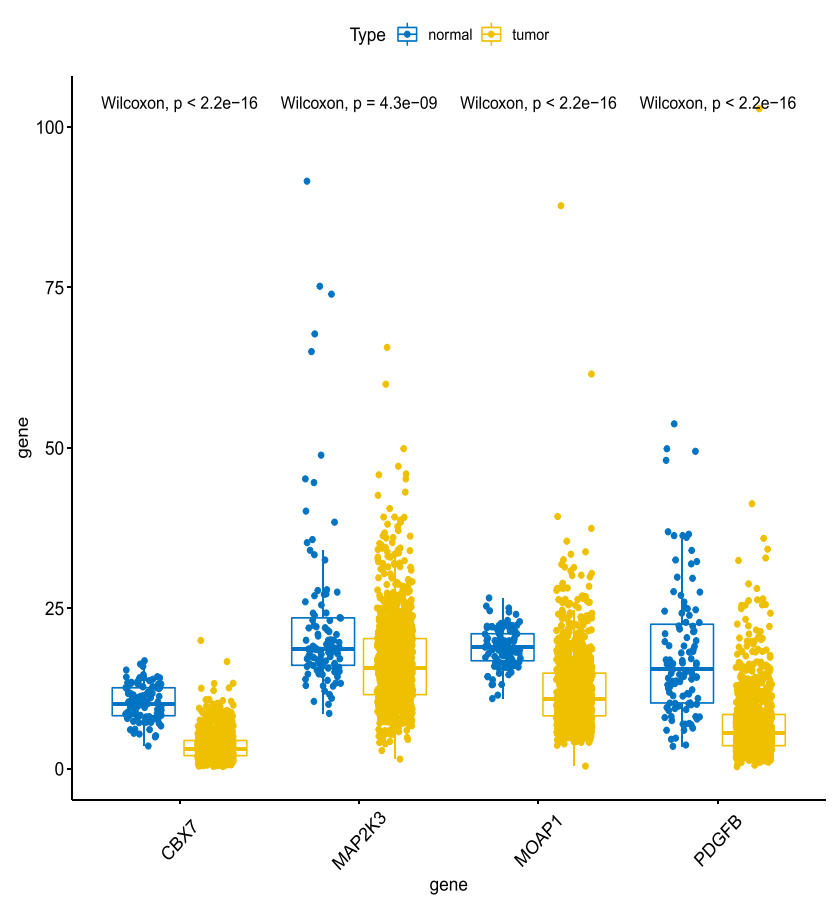

B

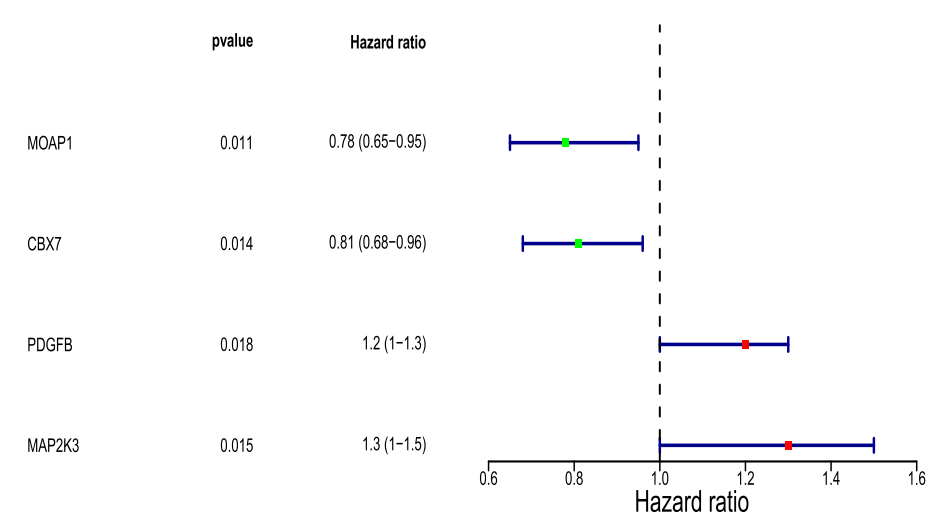

\section{D}

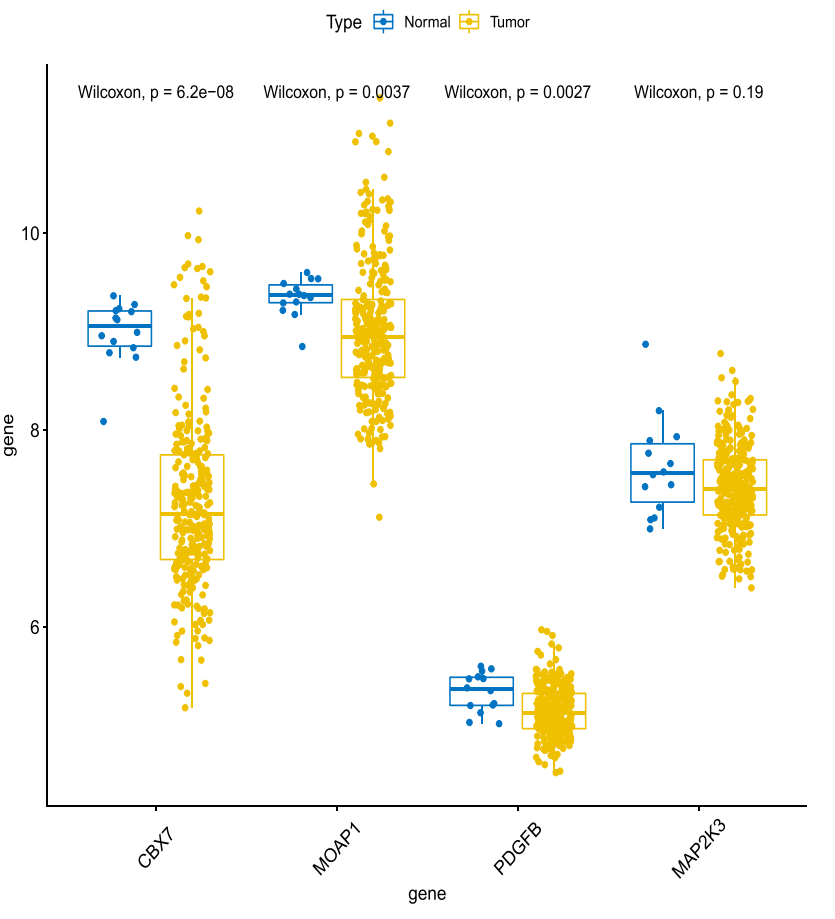

Figure 4 Identification of key genes associated with prognosis of lung cancer. (A) Fourteen genes and (B) four genes were related to prognosis by univariate Cox regression algorithm analysis and multivariate Cox regression algorithm analysis, respectively. The expressions of MOAPI, CBX7, PDGFB, and MAP2K3 were downregulated in both The Cancer Genome Atlas (TCGA) dataset (C) and the GSE30219 lung cancer samples (D). P values less than 0.05 are considered significant.

risk score) to construct a nomogram in TCGA training set (Figure 8A) with a $\mathrm{C}$-index of 0.627 . The calibration curves for the 1-, 3-, 5-, 7-, and 10-year timepoints showed that the predicted overall survival was very close to the actual observed overall survival (Figure 8B), indicating the clinical value of the nomogram. The nomogram was 

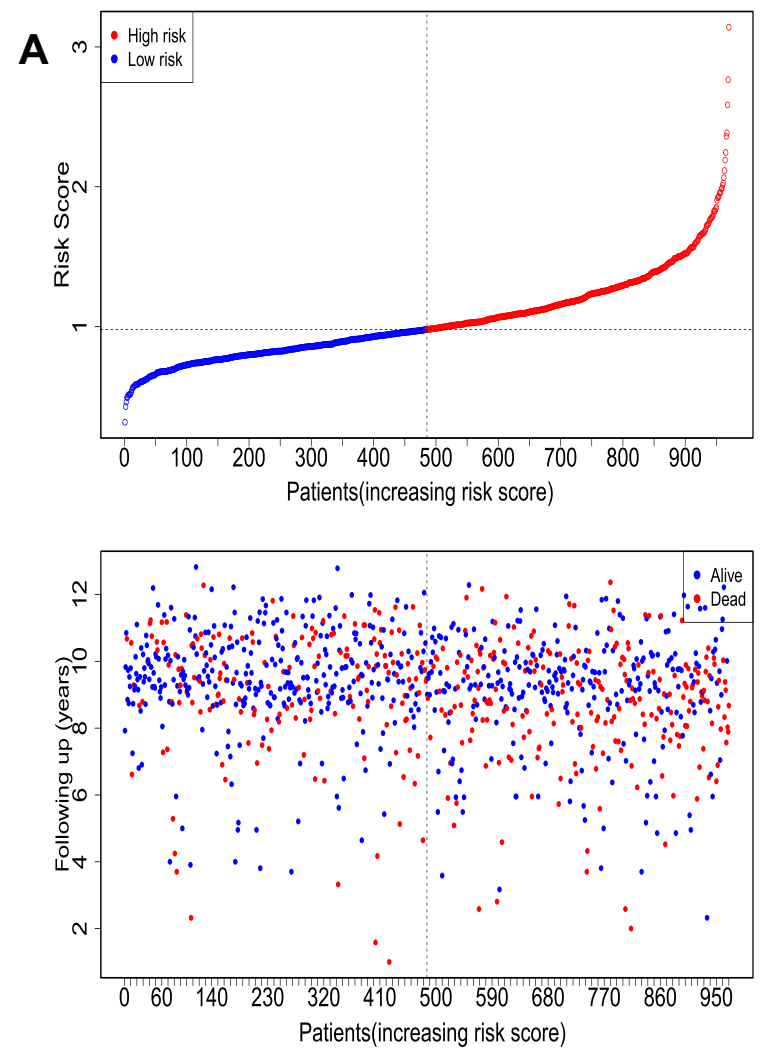

C

Kaplan-Meier Curve for Survival

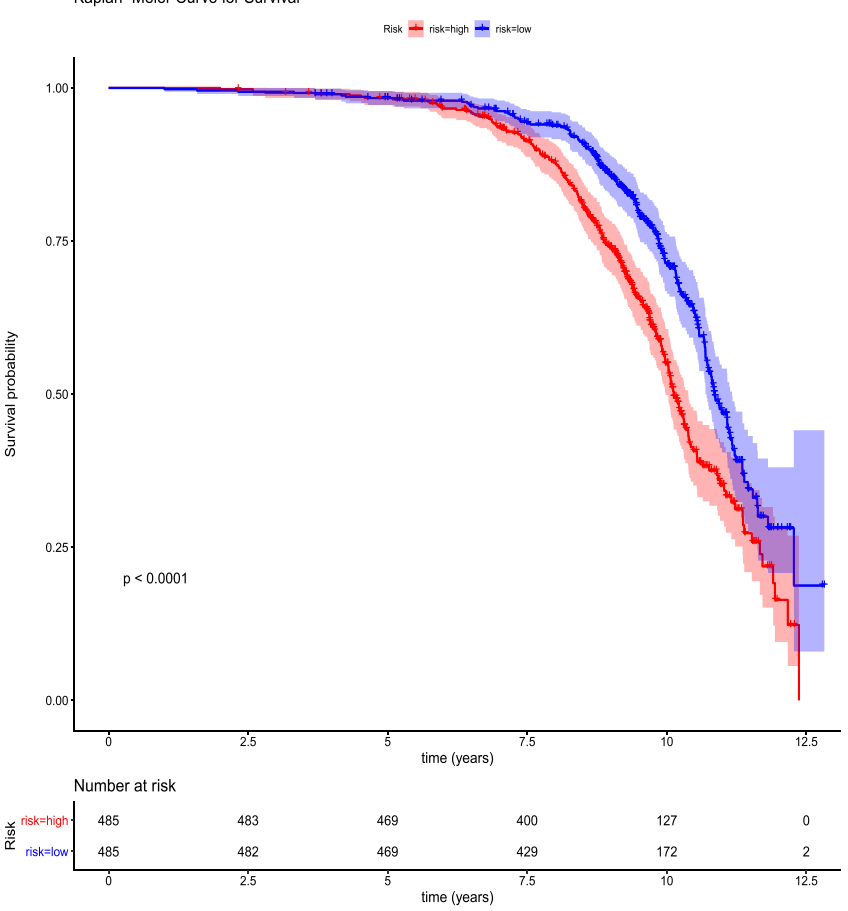

D

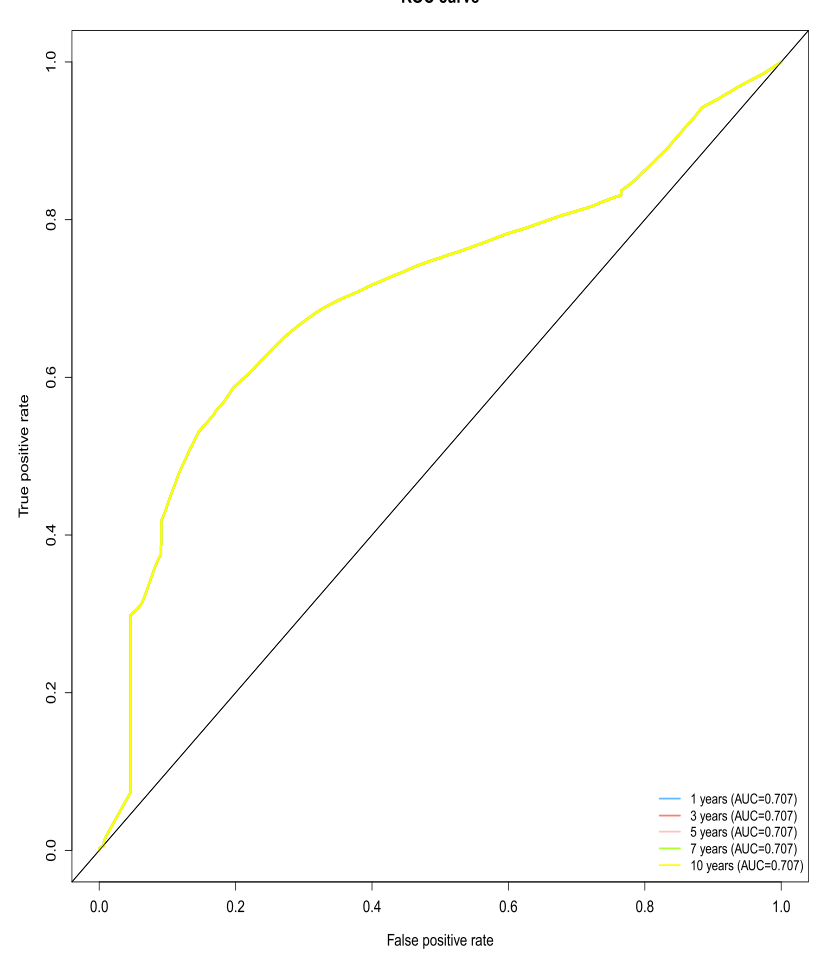

Figure 5 The prognostic assessment of the signature in The Cancer Genome Atlas (TCGA) dataset. (A) Survival status and survival duration of patients and heatmap of the four key prognostic genes expression in patients with lung cancer. (B) The risk score distribution of patients with lung cancer in TCGA dataset. (C) The Kaplan-Meier curve of the overall survival between the high-risk and low-risk groups stratified by the median risk score in TCGA dataset. (D) ROC analysis of the predictive efficiency of the four-gene prognostic model on overall survival based on risk score. Abbreviation: ROC, Receiver operating characteristic curve. 
Table 2 The Coefficients of 4 Key Prognostic Genes

\begin{tabular}{|l|l|l|l|l|l|}
\hline Gene & Coef & HR & HR.95L & HR.95H & P value \\
\hline MOAPI & -0.246353 & 0.781645 & 0.646047 & 0.945705 & 0.011269 \\
CBX7 & -0.215351 & 0.806258 & 0.678934 & 0.957460 & 0.014062 \\
PDGFB & 0.151419 & 1.163484 & 1.026362 & 1.31892 & 0.017948 \\
MAP2K3 & 0.224298 & 1.251444 & 1.043913 & 1.500232 & 0.015329 \\
\hline
\end{tabular}

Abbreviations: coef, coefficients; HR, hazard ratio.

constructed using the risk score and other factors (Figure 8C), and its clinical use (Figure 8D) was confirmed in the GSE30219 validation set.

\section{Exploration of the Molecular Mechanisms of Prognostic Gene Signatures by GSEA}

To elucidate the molecular mechanisms of these prognostic gene signatures, we performed GSEA. Results showed that the differentially expressed genes between the highand low-risk groups based on the risk score model of $M O A P 1, C B X 7, P D G F B$, and $M A P 2 K 3$ were enriched in various biological processes. The top $10 \mathrm{KEGG}$ pathways were the extracellular matrix receptor interaction, focal adhesion, autoimmune thyroid disease, pathways in cancer, cell cycle, asthma, cytokine-cytokine receptor interaction, allograft rejection, regulation of actin cytoskeleton, and small cell lung cancer (Figure 9A). The top 10 GO terms were ameboidal-type cell migration, basement membrane (BM), cadherin binding, cell adhesion molecule binding, cell junction assembly, cell junction organization, cell substrate adhesion, cell substrate junction, chromosome segregation, and collagen binding (Figure 9B).

\section{Discussion}

Lung cancer is the leading cause of tumor-related mortality in the world. Every year, 1.8 million and 1.6 million people are diagnosed with and die of lung cancer, respectively. ${ }^{14}$ Although awareness of lung cancer is increasing, the pathogenesis of lung cancer remains complicated. As previously described, OSA is a prevalent disease characterized by $\mathrm{IH}^{4}{ }^{4}$ In clinical studies, sleep apnea and nocturnal hypoxemia were very common in patients with lung cancer, ${ }^{8}$ and the severity of OSA is significantly related to an increased risk of death in lung cancer. ${ }^{15}$ Much evidence has shown that lung cancer is closely associated with OSA. However, the shared genes and the common pathogenesis of these two diseases are unclear and worthy of more study.
In this study, WGCNA was used to explore shared genes and common mechanisms of lung cancer and OSA. WGCNA has been used to investigate the coexpression module between two diseases in many studies; examples include an exploration of the shared pathogenesis of Alzheimer's disease and type 2 diabetes mellitus and an analysis of shared gene signatures and candidate molecular mechanisms of pemphigus and systemic lupus erythematosus. ${ }^{16,17}$ Through bioinformatic analysis, a total of 104 genes were identified as shared by OSA and lung cancer. Additional functional enrichment analysis showed that positive regulation of blood vessel endothelial cell migration plays an important role in both OSA and lung cancer. A review of many studies have indicated that impairment and dysfunction of circulating endothelial cells are involved in the pathophysiological mechanism of OSA. ${ }^{18}$ In a study of patients with OSA, impairment of human coronary endothelial cell migration was found in severe OSA, which suggests that regulation of blood vessel endothelial cell migration may be involved in OSA. ${ }^{19}$ Moreover, other studies have shown that the migration of blood vessel endothelial cells plays an important role in lung cancer. ${ }^{20}$ An investigation on long noncoding RNA (lncRNA) in NSCLC showed that IncRNA LINC00173.v1 promoted proliferation and migration of vascular endothelial cells, which contributed to tumorigenesis of lung squamous cell carcinoma. ${ }^{20}$ A study focused on metastasis of lung cancer described claudin-5 modification of brain microvascular endothelial cell proliferation, migration, and adhesion to regulate blood-brain barrier permeability, which inhibited metastasis of lung cancer. ${ }^{21}$ The 104 common genes identified in this study may affect OSA and lung cancer through mechanisms related to endothelial and epithelial cell migration.

In this study, univariate and multivariate Cox regression algorithm analyses identified key shared genes. $M O A P 1, C B X 7, P D G F B$, and $M A P 2 K 3$ were identified from these 104 genes. MOAP1 is a $\mathrm{BH} 3$-like protein that plays a critical role in both the intrinsic and extrinsic 
A
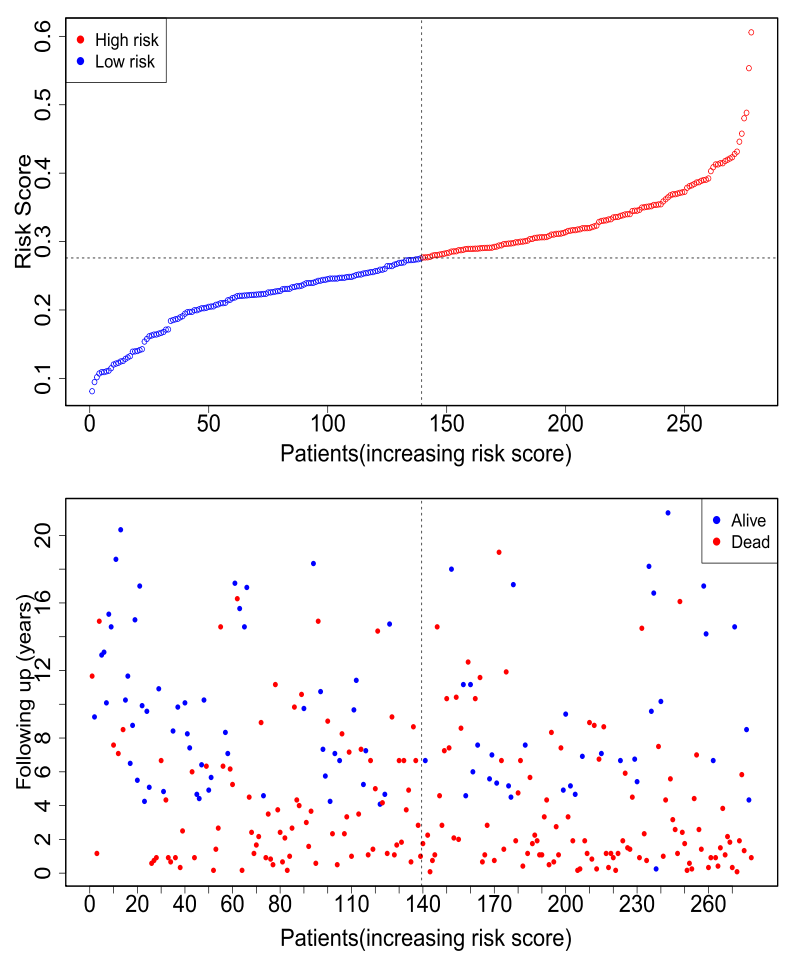

C

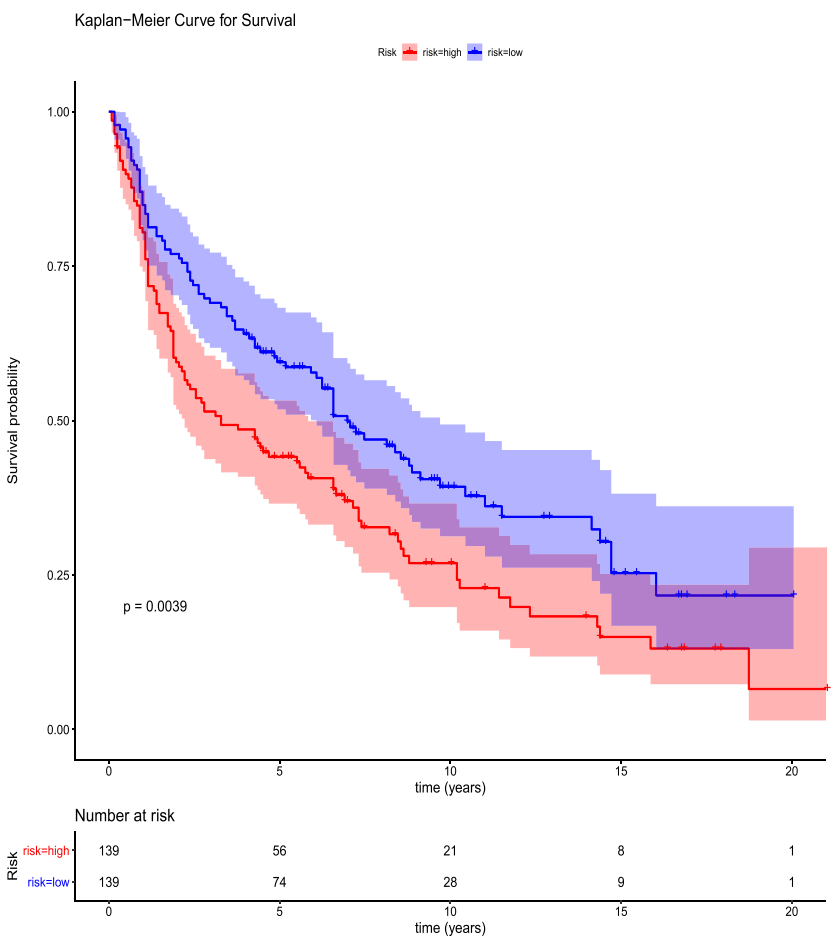

B

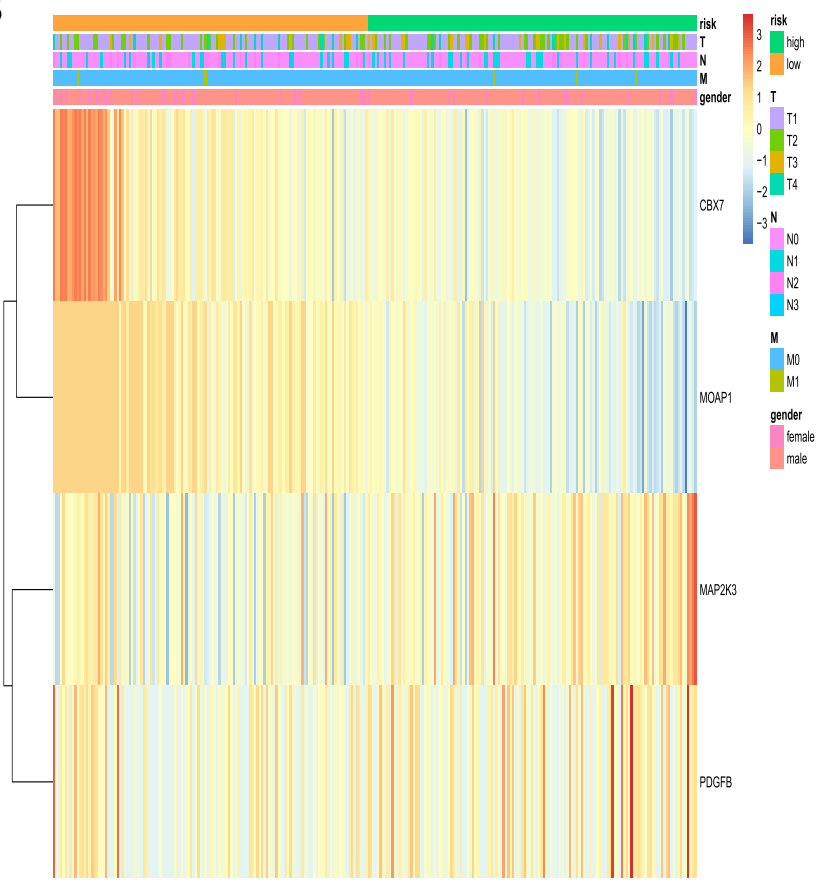

D

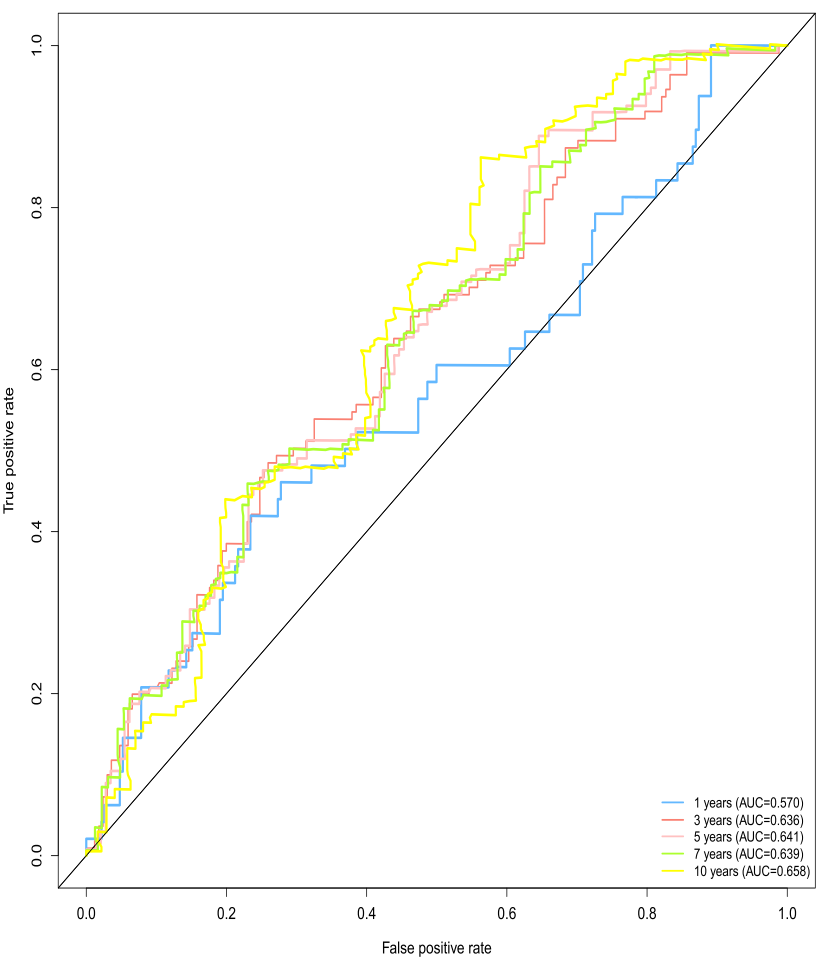

Figure 6 The prognostic assessment of the signature in the GSE30219 dataset. (A) Survival status and survival duration of patients and heatmap of the four key prognostic genes expression in patients with lung cancer. (B) The risk score distribution of patients with lung cancer in the GSE30219 dataset. (C) The Kaplan-Meier curve of the overall survival between the high-risk and low-risk groups stratified by the median risk score in the GSE30219 dataset. (D) ROC analysis of the predictive efficiency of the four-gene prognostic model on overall survival based on risk score.

Abbreviation: ROC, Receiver operating characteristic curve. 


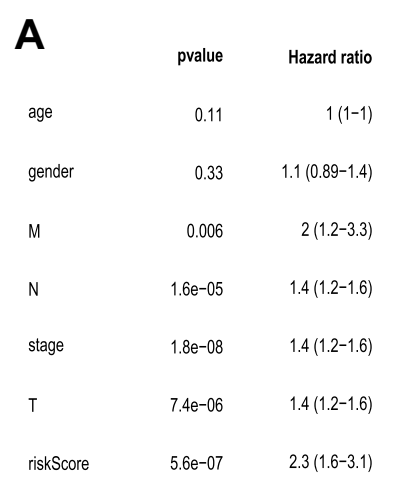

C
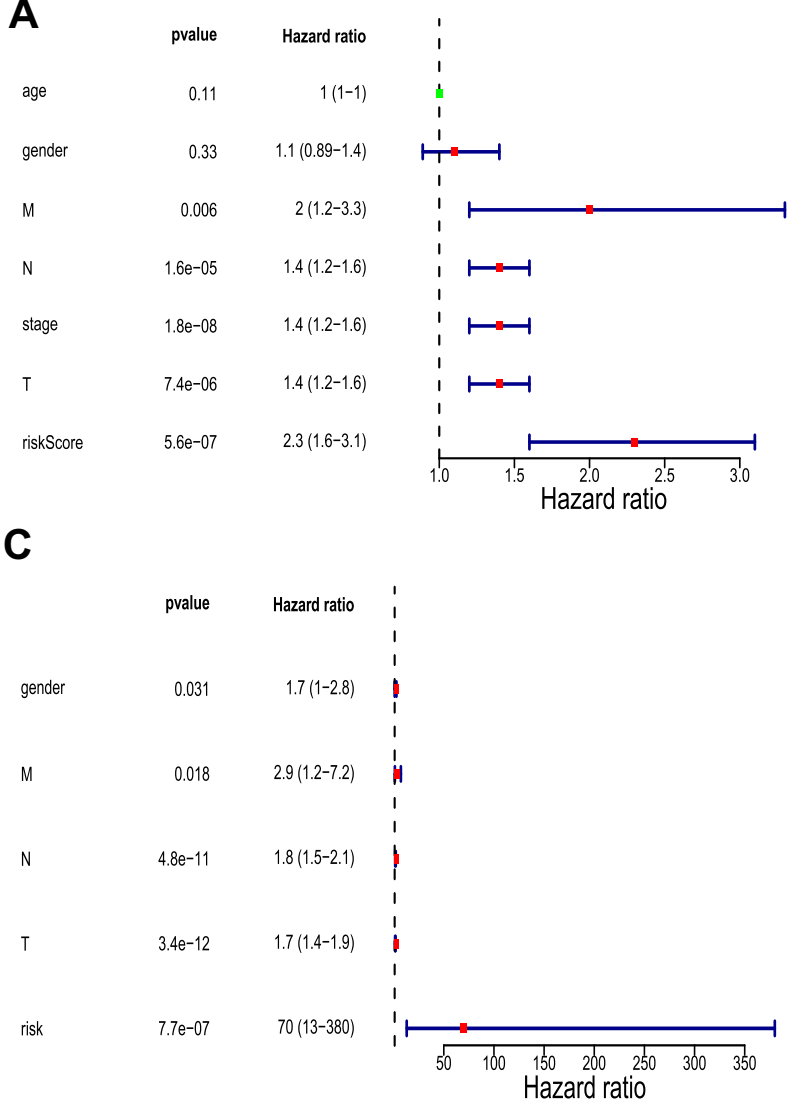

B
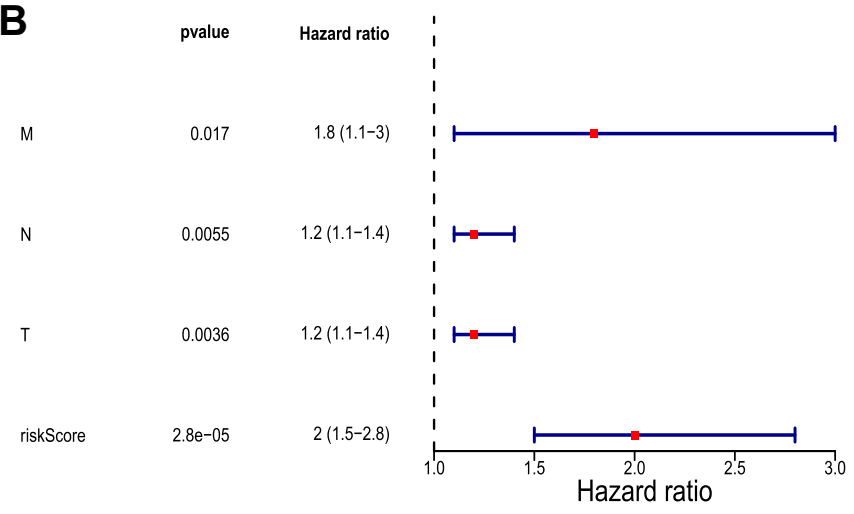

D

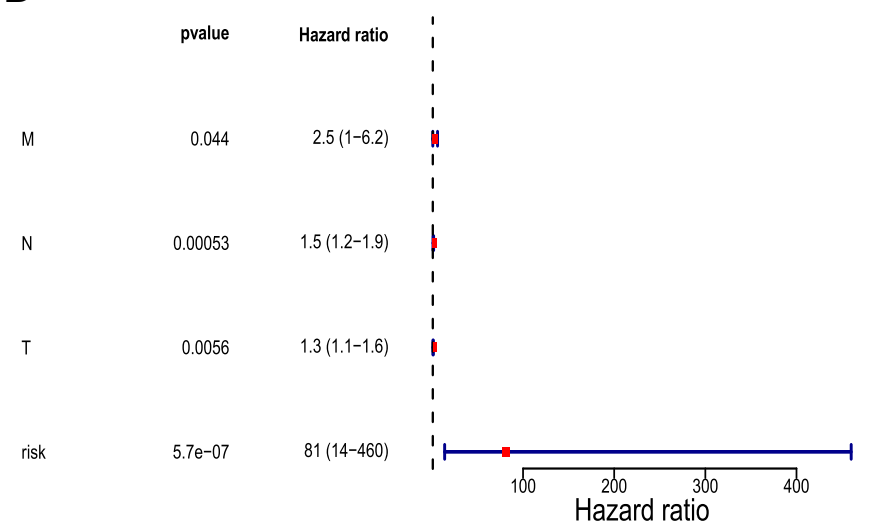

Figure 7 Univariate and multivariate analyses in The Cancer Genome Atlas (TCGA) training set and the GSE30219 validation set. (A) Univariate analysis in TCGA training set. (B) Multivariate analysis in TCGA training set. (C) Univariate analysis in the GSE30219 validation set. (D) Multivariate analysis in the GSE30219 validation set. P values less than 0.05 are considered significant.

modes of cell death or apoptosis. ${ }^{22}$ A study showed that it could act as a tumor suppressor molecule by promoting the apoptosis of tumor cells. ${ }^{23}$ In lung cancer, inhibiting the expression of MOAP1 by microRNA-25 enhanced the proliferation of non-small cell lung cancer (NSCLC) and suppressed apoptosis of NSCLC cells, ${ }^{24}$ which was consistent with the protective role of MOAP1 found in our study. CBX7 belongs to the polycomb group (PCG) family, which participates in the formation of PCG complex 1 to perform biological functions. The inhibitory effect of CBX7 in lung cancer has been demonstrated in some studies. ${ }^{25,26}$ Cacciola et $\mathrm{al}^{27}$ and Pallante et $\mathrm{al}^{28}$ reported that the lack of $C B X 7$ expression in lung cancer tissues was intensively associated with high-grade malignant phenotypes and poor prognosis. Peng et $\mathrm{al}^{29}$ found that inhibiting $C B X 7$ expression by microRNA-19 enhanced the proliferation of lung cancer cells. These studies were also in accordance with the protective role of $C B X 7$ found in our study. PDGFB plays a vital part in recruiting platelet-derived growth factor (PDGF) receptor $\beta$-positive pericytes into blood vessels. ${ }^{30}$ One study has shown that the formation of blood vessels and the progression and metastasis of lung cancer were positively associated with PDGFB. ${ }^{31}$ A study on the biological significance of endothelial cell-derived PDGFB on lung cancer cells found that an increased migration trend of A549 NSCLC cells was related to the use of vascular endothelial growth factor (VEGF)-stimulated (PDGFBrich) conditioned medium. ${ }^{32}$ Furthermore, numerous researchers have determined that the expression of PDGFB was strongly associated with lymph node metastasis and tumor size, and it was a strong and independent prognostic factor in NSCLC. ${ }^{33,34}$ Together, this research is consistent with our analysis.

A study of MAP2K3 in lung cancer found that abnormal methylation was detected in lung cancer cell lines and that $M A P 2 K 3$ expression was upregulated in cancer compared with nonmalignant lung tissues, which suggested that MAP2K3 may be involved in tumorigenesis of lung cancer. ${ }^{35}$ Functional tests showed that knocking down of 
A

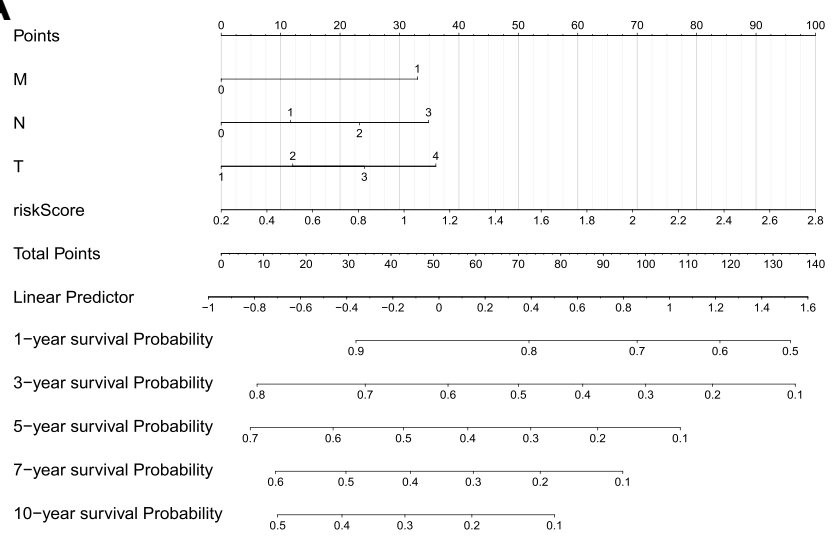

\section{C}

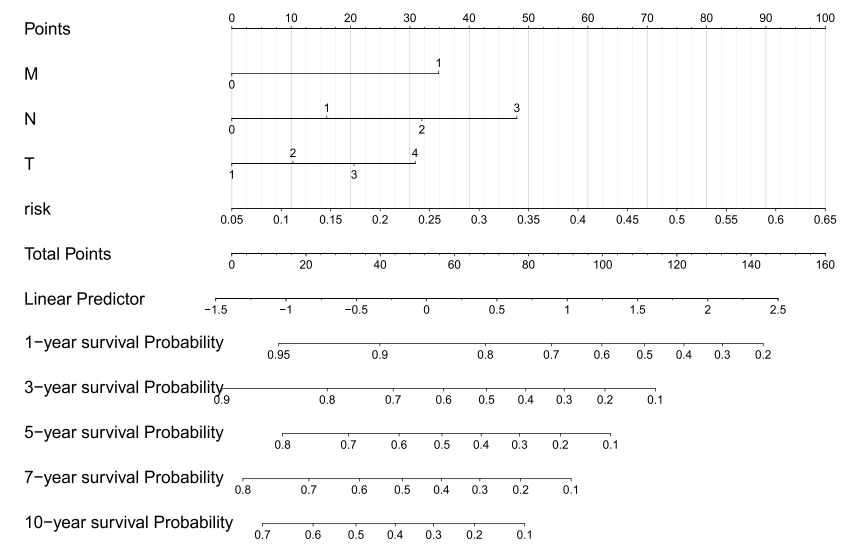

B

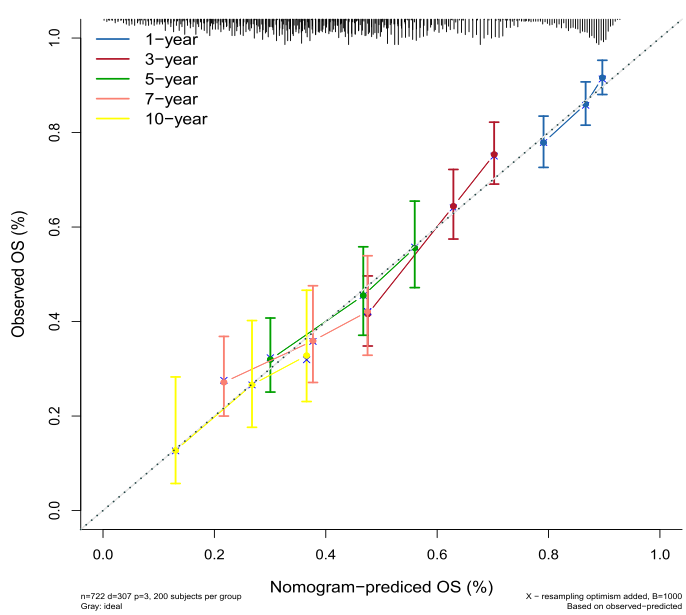

D

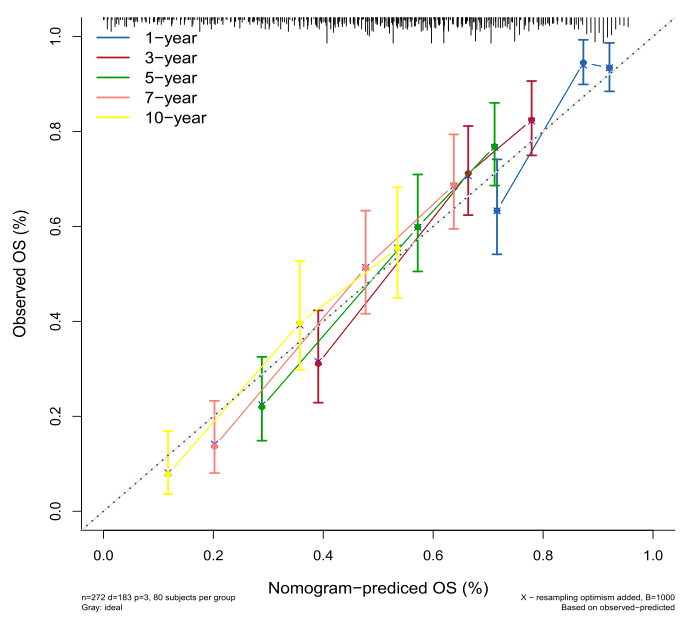

Figure 8 Validation of the nomogram in predicting overall survival of lung cancer in The Cancer Genome Atlas (TCGA) training set and the GSE30219 validation set. (A and C) A nomogram to predict survival probability at the I-, 3-, 5-, 7-, and 10-year timepoints for patients with lung cancer on the basis of results derived from TCGA training and GSE30219 validation sets. (B and D) Calibration curve for the nomogram when predicting the I-, 3-, 5-, 7-, and I0-year overall survival in TCGA training and GSE302I9 validation sets.

MAP2K3 inhibited the proliferation and survival of lung cancer cells, ${ }^{36}$ which was similar to our results. In short, the predictive effects of $M O A P 1, C B X 7, P D G F B$, and $M A P 2 K 3$ identified in this study were consistent with effects in previous studies, which suggest that these four key genes deserve additional study in lung cancer. Furthermore, a risk model and a nomogram were established on the basis of these four key common genes. The risk model and nomogram accurately predicted the overall survival of patients with lung cancer and was validated in another lung cancer data set, indicating that the risk model and nomogram have potential clinical value.

To investigate the possible molecular mechanisms of four key prognostic genes, patients with lung cancer were divided into high-risk and low-risk groups according to risk scores. Then, GSEA was performed to enrich biological processes and signaling pathways in which the differentially expressed genes between high-risk and lowrisk groups were involved. Among the top $10 \mathrm{KEGG}$ pathways, pathways in cancer and small cell lung cancer were obviously related to the tumorigenesis and development of lung cancer. In addition, BM, which was described as in the top two of enriched GO terms, was intensively associated with lung cancer. ${ }^{37}$ Investigations showed that the histologic heterogeneity of lung adenocarcinoma was partly related to the cancer cell-stromal interaction, especially through $\mathrm{BM}$ preservation or destruction. ${ }^{38}$ Moreover, a study of NSCLC found that loss of BM integrity was strongly related to NSCLC, and the loss of $\mathrm{BM}$ integrity was associated with degradation of nidogen1, an essential component of the BM. ${ }^{37}$ Therefore, we speculated that the four key prognostic genes may affect the development of lung cancer through cancer and small cell lung cancer signaling pathways and BM function. 
A

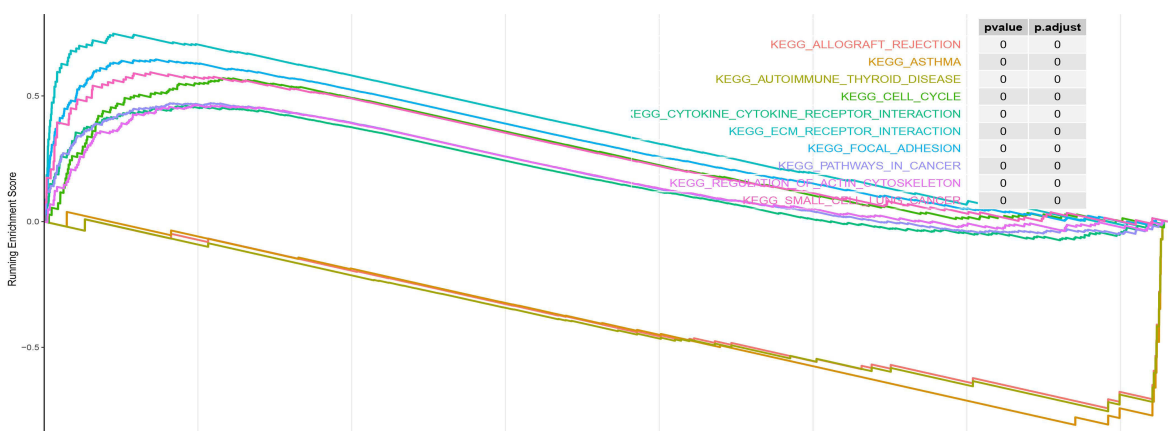

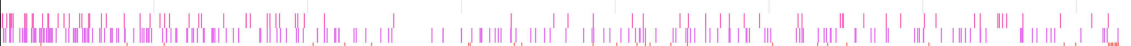

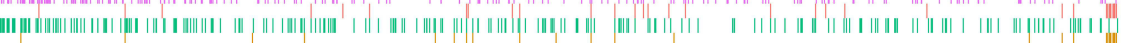

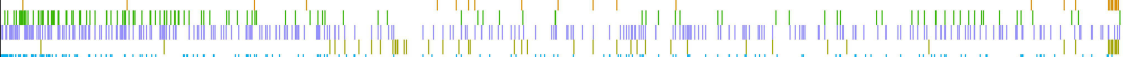

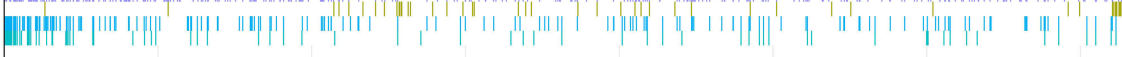

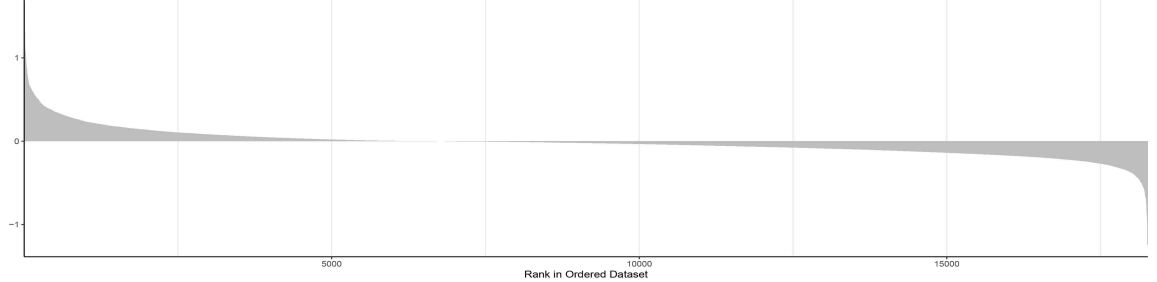

B

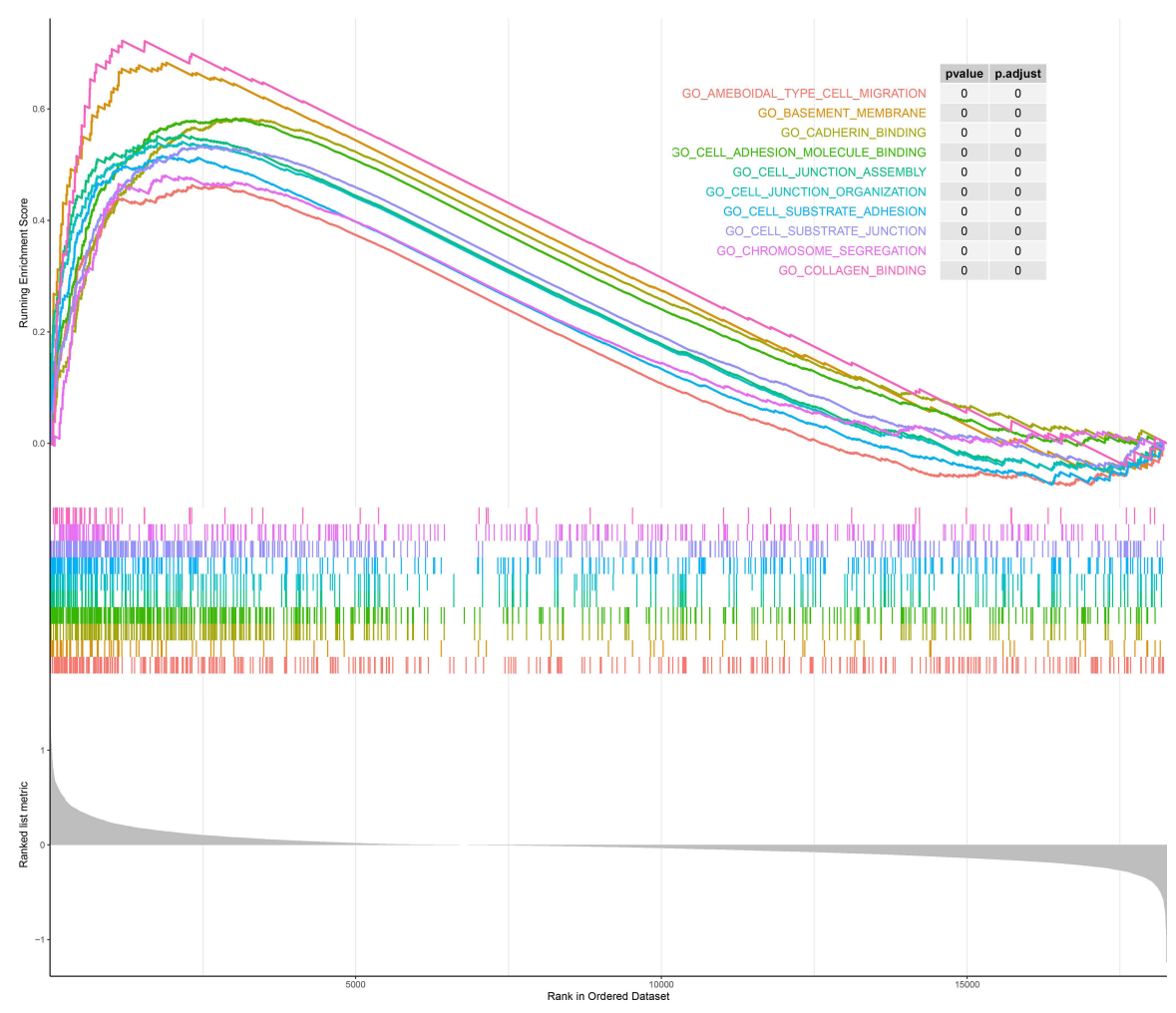

Figure 9 Gene set enrichment analysis between the high- and low-risk groups. (A) The top 10 Kyoto Encyclopedia of Genes and Genomes (KEGG) pathways. (B) The top 10 Gene Ontology (GO) terms.

This study may help clarify the common pathogenesis of lung cancer and OSA. Nevertheless, limitations exist. First, this study was a retrospective analysis based on existing databases. Therefore, a series of prospective studies is necessary to verify the bioinformatics results.
Second, we aimed to find a practical prognosis-predicting model, but it remains rudimentary, so additional exploration is needed. Third, though genes shared by OSA and lung cancer were identified, the biological function of these genes in lung cancer has not yet been fully clarified. 
Work to reveal the pathogenesis of these two diseases at the molecular level remains indispensable.

\section{Conclusion}

In this study, WGCNA was used to explore shared genes, investigate the common mechanisms associated with lung cancer and OSA, and evaluate the prognostic value of these genes in patients with lung cancer. Four key common genes were identified, and a risk model and nomogram were established to predict the prognosis of patients with lung cancer with relatively high accuracy. This study reveals the potential molecular mechanisms of OSA in lung cancer for the first time, providing some new guidance and ideas for additional investigations of these two diseases.

\section{Acknowledgments}

This work was supported by the National Natural Science Foundation of China (Grant No. 81660493) and the Natural Science Foundation of Jiangxi Province (Grants No. 20171BAB205053 and 20202ACBL206019).

\section{Disclosure}

The authors report no conflicts of interest in this work.

\section{References}

1. Siegel RL, Miller KD, Jemal A. Cancer statistics, 2020. CA Cancer J Clin. 2020;70(1):7-30. doi:10.3322/caac.21590

2. Yang D, Liu Y, Bai C, Wang X, Powell CA. Epidemiology of lung cancer and lung cancer screening programs in China and the United States. Cancer Lett. 2020;468:82-87. doi:10.1016/j.canlet.2019.10.009

3. Bade BC, Dela CC. Lung cancer 2020: epidemiology, etiology, and prevention. Clin Chest Med. 2020;41(1):1-24. doi:10.1016/j.ccm.20 19.10.001

4. Rundo JV. Obstructive sleep apnea basics. Cleve Clin J Med. 2019;86 (9Suppl 1):2-9. doi:10.3949/ccjm.86.s1.02

5. Yang X, Niu X, Xiao Y, Lin K, Chen X. MiRNA expression profiles in healthy OSAHS and OSAHS with arterial hypertension: potential diagnostic and early warning markers. Respir Res. 2018;19(1):194. doi:10.1186/s12931-018-0894-9

6. Ko CY, Liu QQ, Su HZ, et al. Gut microbiota in obstructive sleep apnea-hypopnea syndrome: disease-related dysbiosis and metabolic comorbidities. Clin Sci (Lond). 2019;133(7):905-917. doi:10.1042/ CS20180891

7. Huang T, Lin BM, Stampfer MJ, et al. Associations of self-reported obstructive sleep apnea with total and site-specific cancer risk in older women: a prospective study. Sleep. 2020;16(7):1091-1098. doi:10. 1093/sleep/zsaa198

8. Cabezas E, Pérez-Warnisher MT, Troncoso MF, et al. Sleep disordered breathing is highly prevalent in patients with lung cancer: results of the sleep apnea in lung cancer study. Respiration. 2019;97(2):119-124. doi:10.1159/000492273

9. Seijo LM, Pérez-Warnisher MT, Giraldo-Cadavid LF, et al. Obstructive sleep apnea and nocturnal hypoxemia are associated with an increased risk of lung cancer. Sleep Med. 2019;63:41-45. doi:10. 1016/j.sleep.2019.05.011
10. Torres M, Martinez-Garcia MÁ, Campos-Rodriguez F, et al. Lung cancer aggressiveness in an intermittent hypoxia murine model of postmenopausal sleep apnea. Menopause. 2020;27(6):706-713. doi:10.1097/GME.0000000000001526

11. Langfelder P, Horvath S. WGCNA: an R package for weighted correlation network analysis. BMC Bioinform. 2008;9(1):559. doi:10. 1186/1471-2105-9-559

12. Zhang B, Horvath S. A general framework for weighted gene co-expression network analysis. Stat Appl Genet Mol Biol. 2005;4 (1):17. doi:10.2202/1544-6115.1128

13. Yu G, Wang LG, Han Y, He QY. clusterProfiler: an R package for comparing biological themes among gene clusters. Omics. 2012;16 (5):284-287. doi:10.1089/omi.2011.0118

14. Hirsch FR, Scagliotti GV, Mulshine JL, et al. Lung cancer: current therapies and new targeted treatments. Lancet. 2017;389(100 66):299-311. doi:10.1016/S0140-6736(16)30958-8

15. Li L, Lu J, Xue W, et al. Target of obstructive sleep apnea syndrome merge lung cancer: based on big data platform. Oncotarget. 2017;8 (13):21567-21578. doi:10.18632/oncotarget. 15372

16. Zhu Y, Ding X, She Z, et al. Exploring shared pathogenesis of Alzheimer's disease and type 2 diabetes mellitus via co-expression networks analysis. Curr Alzheimer Res. 2020;17(6):566-575. doi:10.2174/1567205017666200810164932

17. Sezin T, Vorobyev A, Sadik CD, Zillikens D, Gupta Y, Ludwig RJ. Gene expression analysis reveals novel shared gene signatures and candidate molecular mechanisms between pemphigus and systemic lupus erythematosus in CD4(+) T cells. Front Immunol. 2017;8:1992. doi:10.3389/fimmu.2017.01992

18. Stiefel P, Sánchez-Armengol MA, Villar J, Vallejo-Vaz A, MorenoLuna R, Capote F. Obstructive sleep apnea syndrome, vascular pathology, endothelial function and endothelial cells and circulating microparticles. Arch Med Res. 2013;44(6):409-414. doi:10.1016/j. arcmed.2013.08.005

19. Hoffmann M, Wolf J, Szyndler A, Singh P, Somers VK, Narkiewicz K. Serum of obstructive sleep apnea patients impairs human coronary endothelial cell migration. Arch Med Sci. 2017;13 (1):223-227. doi:10.5114/aoms.2015.56490

20. Chen J, Liu A, Wang Z, et al. LINC00173.v1 promotes angiogenesis and progression of lung squamous cell carcinoma by sponging miR-511-5p to regulate VEGFA expression. Mol Cancer. 2020;19 (1):98. doi:10.1186/s12943-020-01217-2

21. Ma SC, Li Q, Peng JY, et al. Claudin-5 regulates blood-brain barrier permeability by modifying brain microvascular endothelial cell proliferation, migration, and adhesion to prevent lung cancer metastasis. CNS Neurosci Ther. 2017;23(12):947-960. doi:10.1111/ cns. 12764

22. Law J, Yu VC, Baksh S. Modulator of Apoptosis 1: a highly regulated RASSF1A-interacting BH3-like protein. Mol Biol Int. 2012;2012:536802. doi:10.1155/2012/536802

23. Law J, Kwek I, Svystun O, et al. RACK1/TRAF2 regulation of modulator of apoptosis-1 (MOAP-1). Biochim Biophys Acta Mol Cell Res. 2018;1865(5):684-694. doi:10.1016/j.bbamcr.2018.02. 006

24. Wu T, Chen W, Kong D, et al. miR-25 targets the modulator of apoptosis 1 gene in lung cancer. Carcinogenesis. 2015;36 (8):925-935. doi:10.1093/carcin/bgv068

25. Forzati F, Federico A, Pallante P, Fedele M, Fusco A. Tumor suppressor activity of CBX7 in lung carcinogenesis. Cell Cycle. 2012;11 (10):1888-1891. doi:10.4161/cc.20022

26. Forzati F, Federico A, Pallante P, et al. CBX7 is a tumor suppressor in mice and humans. $J$ Clin Invest. 2012;122(2):612-623. doi:10.1172/ JCI58620

27. Cacciola NA, Sepe R, Forzati F, et al. Restoration of CBX7 expression increases the susceptibility of human lung carcinoma cells to irinotecan treatment. Naunyn Schmiedebergs Arch Pharmacol. 2015;388(11):1179-1186. doi:10.1007/s00210-015-1153-y 
28. Pallante P, Sepe R, Federico A, Forzati F, Bianco M, Fusco A. CBX7 modulates the expression of genes critical for cancer progression. PLoS One. 2014;9(5):e98295. doi:10.1371/journal. pone.0098295

29. Peng X, Guan L, Gao B. miRNA-19 promotes non-small-cell lung cancer cell proliferation via inhibiting $\mathrm{CBX} 7$ expression. Onco Targets Ther. 2018;11:8865-8874. doi:10.2147/OTT.S181433

30. Fredriksson L, Li H, Eriksson U. The PDGF family: four gene products form five dimeric isoforms. Cytokine Growth Factor Rev. 2004;15(4):197-204. doi:10.1016/j.cytogfr.2004.03.007

31. Wagner KD, Du S, Martin L, Leccia N, Michiels JF, Wagner N. Vascular PPAR $\beta / \delta$ promotes tumor angiogenesis and progression. Cells-Basel. 2019;8(12):1623. doi:10.3390/cells8121623

32. Reinmuth N, Rensinghoff S, Raedel M, et al. Paracrine interactions of vascular endothelial growth factor and platelet-derived growth factor in endothelial and lung cancer cells. Int J Oncol. 2007;31 (3):621-626.

33. Donnem T, Andersen S, Al-Saad S, Al-Shibli K, Busund LT, Bremnes RM. Prognostic impact of angiogenic markers in nonsmall-cell lung cancer is related to tumor size. Clin Lung Cancer. 2011;12(2):106-115. doi:10.1016/j.cllc.2011.03.005
34. Donnem T, Al-Saad S, Al-Shibli K, Busund LT, Bremnes RM. Coexpression of PDGF-B and VEGFR-3 strongly correlates with lymph node metastasis and poor survival in non-small-cell lung cancer. Ann Oncol. 2010;21(2):223-231. doi:10.1093/annonc/mdp296

35. Park JC, Chae YK, Son $\mathrm{CH}$, et al. Epigenetic silencing of human $\mathrm{T}$ (brachyury homologue) gene in non-small-cell lung cancer. Biochem Biophys Res Commun. 2008;365(2):221-226. doi:10.1016/ j.bbrc.2007.10.144

36. Gurtner A, Starace G, Norelli G, Piaggio G, Sacchi A, Bossi G. Mutant p53-induced up-regulation of mitogen-activated protein kinase 3 contributes to gain of function. J Biol Chem. 2010;285 (19):14160-14169. doi:10.1074/jbc.M109.094813

37. Willumsen N, Bager CL, Leeming DJ, Bay-Jensen AC, Karsdal MA. Nidogen-1 degraded by cathepsin $\mathrm{S}$ can be quantified in serum and is associated with non-small cell lung cancer. Neoplasia. 2017;19 (4):271-278. doi:10.1016/j.neo.2017.01.008

38. Matsuo Y, Hashimoto S, Koga T, et al. Growth pattern correlates with the distribution of basement membrane and prognosis in lung adenocarcinoma. Pathol Res Pract. 2004;200(7-8):517-529. doi:10.1016/j.prp.2004.05.002

\section{Publish your work in this journal}

The International Journal of General Medicine is an international, peer-reviewed open-access journal that focuses on general and internal medicine, pathogenesis, epidemiology, diagnosis, monitoring and treatment protocols. The journal is characterized by the rapid reporting of reviews, original research and clinical studies across all disease areas. The manuscript management system is completely online and includes a very quick and fair peer-review system, which is all easy to use. Visit http://www.dovepress.com/ testimonials.php to read real quotes from published authors. 